\title{
Representació gràfica i ècfrasi en l’obra de Ramon Llull
}

\author{
Anthony Bonner, Albert Soler \\ Centre de Documentació Ramon Llull, Universitat de Barcelona \\ ab@anthonybonner.com \\ http://orcid.org/OOOO-OOOI-9054-0075 \\ albert.soler@ub.edu \\ http://orcid.org/oOOO-OOO3-4III-3I $6 \mathrm{X}$
}

Rebut 23/02/2016; acceptat 20/03/20I6

DOI Io.7203/MCLM.3.8062

\section{Graphical representation and ekphrasis in Ramon Llull's work}

\begin{abstract}
This article discusses the relation established between texts and graphic representations in works of Ramon Llull, paying special attention to a rhetorical device called ekphrasis, that is, the verbal description of a visual object. It analyzes descriptions of Lullian figures, and especially of arborial diagrams, in the presence of their representation (referential ekphrasis) or in the absence of same (notional ekphrasis). We conclude that the material aspect of the figures as well as the mental assimilation of their funcion are key elements in the process of cognitive elevation proposed by Llull.
\end{abstract}

\section{KEYWORDS}

Ramon Llull; Lullian figures; ekphrasis; diagrammatics; medieval rhetoric.

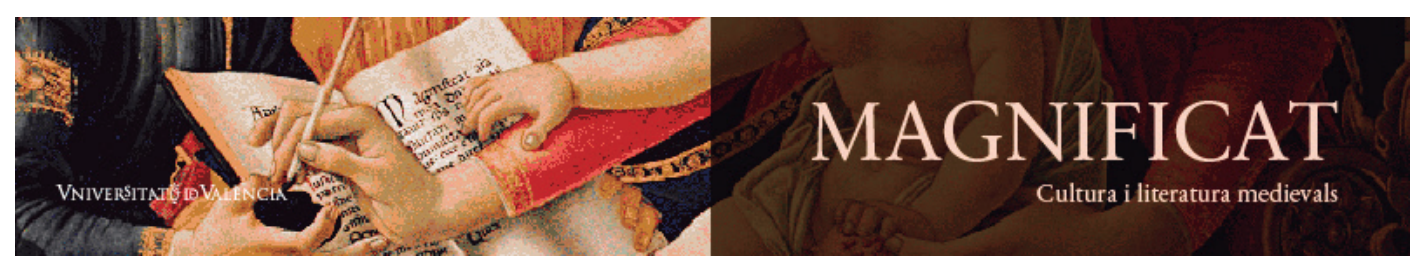

Magnificat Cultura i Literatura Medievals 3, 20I6, 67-93. http://ojs.uv.es/index.php/MCLM

ISSN 2386-8295 
RESUM

El present treball estudia la relació que s'estableix entre text i representacions gràfiques en les obres de Ramon Llull, fent una atenció especial al recurs retòric anomenat ècfrasi, això és, la descripció verbal d'un objecte visual. S’analitzen casos de descripció de figures lul-lianes, sobretot esquemes arboris, en presència de la seva representació (ècfrasi referencial) o en absència de la mateixa (ècfrasi nocional). Es conclou que la dimensió material de les figures i l’assimilació mental del seu funcionament són elements cabdals del procés d’elevació cognitiva que proposa Llull

PARAULES CLAU

Ramon Llull; figures lul.lianes; ècfrasi: diagramàtica; retòrica medieval.

Bonner, Anthony; Soler, Albert. 20I6. "Representació gràfica i ècfrasi en l'obra de Ramon Llull”, Magnificat Cultura i Literatura Medievals, 3: 67-93

\section{TAULA DE CONTINGUTS}

oIntroducció -69

I Interacció entre text i imatge: I'ècfrasi referencial - 7I

2 La construcció mental de la imatge: ècfrasi nocional - 74

${ }_{3}$ Un desenvolupament peculiar del discurs ecfràstic - 80

4 A mode de conclusió - 86

5 Annex: Descripció de l'arbre dels Començaments de medicina - 89

6 Obres citades $-9 \mathrm{I}$ 


\section{b米}

\section{o Introducció}

Una de les peculiaritats de les obres de Ramon Llull que més han cridat l'atenció dels estudiosos és la utilització d'una àmplia gamma de recursos diagramàtics -figures circulars, arbres, taules, etc.- que acompanyen el text de molts dels seus llibres. La relació que s'estableixen entre text i representacions gràfiques, tanmateix, varia molt entre unes obres i altres. Així, a l'Ars compendiosa inveniendi veritatem (c. I274), que és la primera versió de l'Art i la primera obra on les figures tenen un paper fonamental, Llull presenta cada figura envoltada d'un text que actua com a glossa de la imatge, sense donar cap descripció pròpiament dita del gràfic. ${ }^{I}$ En canvi, a la segona versió de l'Art, l'Art demostrativa (c. I283) el procediment és completament invers: les figures s'agrupen a l'inici de l'obra en un quadern independent i al mateix temps es descriuen minuciosament en el cos del text. Com a mostra, triarem una de les figures de l'Art demostrativa, la Figura V de les virtuts i els vicis, amb la seva descripció:

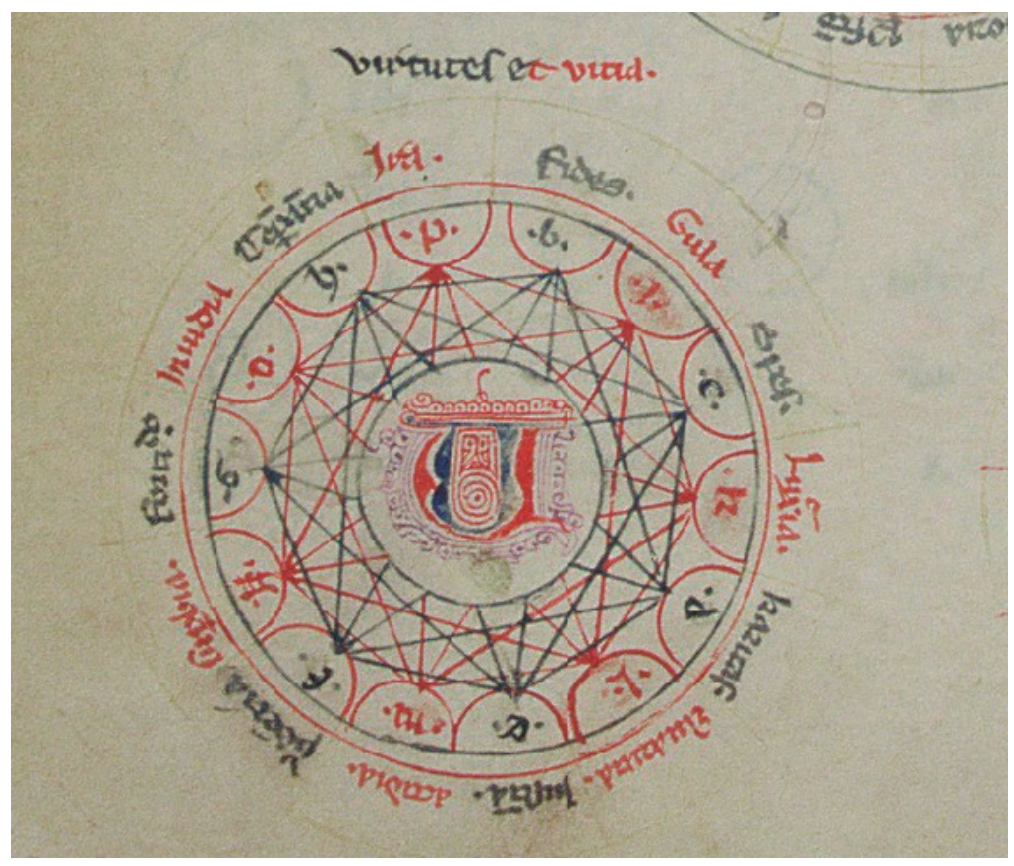

I. Venècia, Marciana VI 200, f. $3 \mathrm{~V}$

(C) Biblioteca Nazionale Marciana. http://tinyurl.com/zbv86jo

La primera figura es circular e es conposta de de ·xiiij cambres: les ·vij. son de vertutz, e les ·vij. son de visis, segons que apar en la circular figura, la qual es en lo comensament de la Art. Les ·vij vertutz son: fe, esperansa, caritat, justicia, prudencia, fortitudo, trempansa; e aquestes ·vij· vertutz son anomenades en esta Art "V blava", per so cor son de blava color. Los ·vij. viscis son lo ·vij· peccatz mortals: gola, lucxuria, avaricia, erguyl, accidia, enveja, ira; e son apelatz en esta Art "V vermella"

I. Per aquesta qüestió a l'Ars compendiosa inveniendi veritatem, vid. Bonner-Soler 2007. Per a les representacions gràfiques en el Llibre de contemplació, que és anterior a l’Art, vid. Soler-Bonner 2016. 
per so cor son de vermella color. ${ }^{2}$

En esta figura a linyes blaves e vermelles, e la $\mathrm{V}$ està en lo mig. Les linyes blaves signifiquen que totes les vertutz se concorden en $\cdot \mathrm{ij} .{ }^{\mathrm{es}}$ maneres: $\mathrm{La} \cdot \mathrm{j} \cdot \mathrm{a}$ manera es con se concorden enfre elles metexes, l'autra es con se concorden contra.ls viscis. E asò metex se seguex dels viscis, los quals an linyes vermelles, concordans-se en sí metexs e contrarians a les vertutz.

La descripció és prou minuciosa però, tot i així, la versió llatina de l'obra encara introdueix una precisió remarcable a l'inici del segon paràgraf, que és molt probable que es degui a una amplificació del mateix Llull:

In hac autem figura sunt lineae transuersales liuidae et rubeae. V uero existens medium rubeum et medium liuidum in linearum medio situatur, significans, per hoc quod est liuidum et rubeum, quod ipsas uirtutes et uitia comprehendit. Sed lineae liuidae transuersales, tendentes ab una camera uirtutis in alteram, significant et ostendunt, quod omnes uirtutes duobus modis sunt concordes ... ${ }^{3}$

És a dir, s’explica no només de quins colors han de ser les línies, sinó també la coloració doble de la lletra $\mathrm{V}$, al centre, la meitat de la qual és blava i l'altra meitat vermella; aquest detall s'ha executat fidelment en la figura corresponent del manuscrit de Venècia, el més antic que conserva l'aparat de figures. D’altra banda, no ha de passar per alt la remissió de la descripció a la representació gràfica de la figura: "segons que apar en la circular figura, la qual es en lo comensament de la Art". Descripcions similars s'ofereixen de la resta de les nou figures principals de l'Art demostrativa.

La descripció verbal d'un objecte visual és un procediment retòric clàssic que hom coneix com a ècfrasi -Ék $\varphi p a \sigma 1 \zeta$ en grec-, que en els tractats llatins de retòrica es traduïa per descriptio. L'exemple clàssic és la descripció minuciosa de l'escut d'Aquil.les a la Ilíada d'Homer (XVIII, vv. $47^{8}-97$ i 5o8-22); i en la literatura llatina, el poema 64 de Catul, que descriu una vànova amb la història d'Ariadna. A l'Edat Mitjana, més que recursos purament retòrics, els discursos ecfràstics són exercicis d'ajuda per a la meditació i la contemplació. Aquest és el sentit del Lignum vitae de sant Bonaventura, on es diu al lector, "describe igitur in spiritu mentis tuae arborem quandam" $i$, a continuació, el guia en la construcció del dibuix mental. ${ }^{4}$ L'ècfrasi medieval no necessàriament es limitava a la descripció d'objectes estàtics, sinó que, precisament per la seva aplicació a exercicis meditatius, podia aplicar-se al desenvolupament d'escenes dinàmiques que el lector o l'oient havia de seguir mentalment. ${ }^{5}$

A l'obra de Ramon Llull tenim nombrosos exemples de discursos ecfràstics. ${ }^{6}$ En aquest estudi,

2. En aquesta obra, Llull evita els mots "virtuts" o "vicis", que generalment substitueix pels termes "V blava" $\mathrm{i}$ "V vermella".

3. Per a la versió catalana vid. Galmés ed. 1932: 13-I4, Bonner ed. 1989: I, 299-300 (en aquesta última s’introdueix l'amplificació del text llatí entre parèntesis angulats); per a la versió llatina, Rubio ed. 2007: 23-24. Per la relació entre les dues versions (en manuscrits sortits del mateix obrador lul.lià), vid. ibid., LX-LXIII.

4. Citat per Carruthers 2006: 288; vid. la traducció catalana de l'obra a Boadas ed. 1994: I73-2I3. Un altre exemple que proposa la mateixa autora (Carruthers 2006: 292) és el De arca Noe mystica (també conegut com Libellus de formatione arche o De Picture arche) d'Hug de Sant Victor, en el qual es donen instruccions molt detallades de com executar la mena de plànol arquitectònic que l'autor proposa. Carruthers assenyala que sovint es preferia l'ècfrasi a la representació gràfica pels efectes que tenia en el lector o oient, que s'havia d'esforçar a representar la imatge mentalment com a exercici mnemònic i meditatiu.

5. Vid. Barbetti 20II, que estudia el recurs a l'ècfrasi en el report de visions en somnis i místiques.

6. Per exemple, als capítols 352-57 del Llibre de contemplació, Llull desenvolupa un mètode particular de contemplació inspirat en els quatre sentits de l'Escriptura de l'exegesi bíblica; els textos narratius que exemplifiquen aquesta nova teoria de l'al-legoria presenten una imatgeria llampant i sorprenent que podria haver estat objecte d'il-lustracions fantàstiques. En canvi, Llull opta per desenvolupar una descripció completament discursiva de manera 
tanmateix, ens centrarem en l'ús -o en el no ús- de l'ècfrasi vinculada a les figures lul-lianes, perquè ens sembla remarcable que Ramon no utilitzi aquest recurs de forma constant i sistemàtica: unes vegades, presenta els seus diagrames sense cap descripció, com ja hem dit; d’altres, acompanyats de descripció, com acabem de mostrar; i, encara d'altres, amb una exposició detallada de la forma i del funcionament de les figures però sense cap representació gràfica. En el segon d'aquests tres casos es tractaria d'una ècfrasi "referencial", que descriu un gràfic present en l'obra; mentre que en el tercer cas es tractaria d’una ècfrasi “nocional”, la descripció d’una figura purament mental.?

\section{Interacció entre text i imatge: l'ècfrasi referencial}

$\mathrm{L}$ a descripció de figures en presència de la seva representació gràfica comporta una interacció entre text i imatge. Llull mateix ho expressa al principi de la descripció de la figura de l'arbre als Començaments de medicina: "Natura es d'enteniment que entena mils per demostració feta per vista et per oiment, que per oir tan solament". ${ }^{8}$

Així que, per al beat, la conjunció de les dues presentacions, verbal i gràfica, és preferible, i per tant és normal en les obres de l'Art a partir de l'Art demostrativa. Però no tenen necessàriament un pes igual: si bé la presentació verbal no exclou necessàriament la gràfica, ${ }^{9}$ la descripció verbal és capaç de proporcionar informació que la il-lustració física no pot transmetre. Com a exemple, compararem el tractament de la Figura A a l'Art demostrativa i a l'Art breu, amb les seves il.lustracions i descripcions:

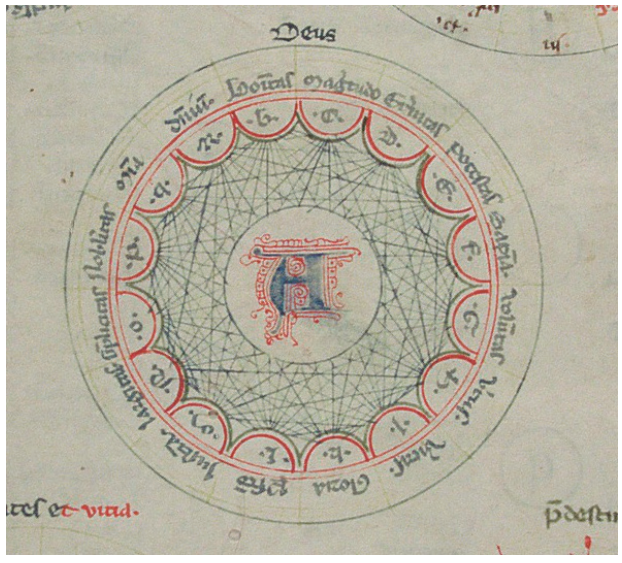

2. Venècia, Marciana VI 200, f. $3 \mathrm{~V}$

(C) Biblioteca Nazionale Marciana http://tinyurl.com/zbv86jo

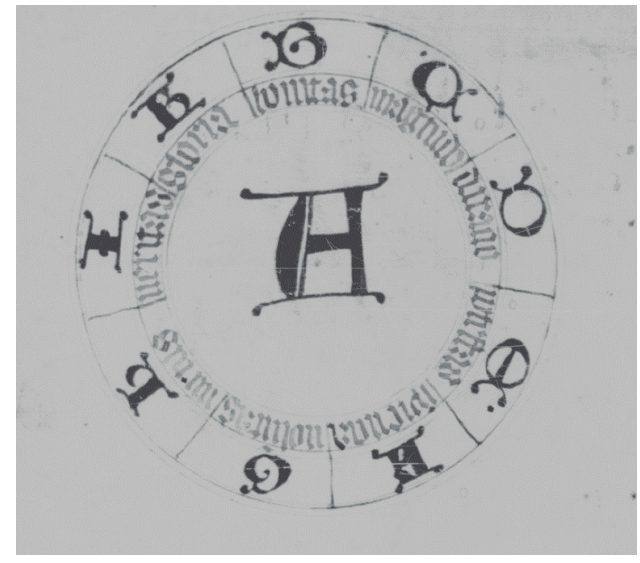

3. Munic, Clm. IO5O6, f. IV CCo

http://tinyurl.com/hvndbrr

que el lector hagi de formar-se una idea mental del que se li exposa. El més destacat és "Lo contrast qui és enfre el cos e l'anima", del capítol 354, que posa en escena tres donzelles i una bèstia de dos caps, que pugen i baixen als extrems

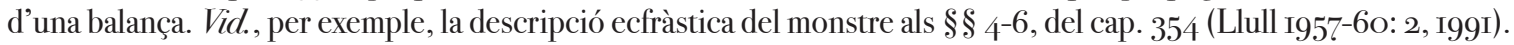
Vid. Rubio 2007 per a una anàlisi d'aquest capítol i Rubio I997 per al component d'artes memoriae d'aquesta part del Llibre de contemplació. Un altre cas de discurs ecfràstic el donaria la descripció que fa Llull al capítol 57 del Llibre de meravelles d'una obra totalment fictícia, el Llibre de plaent visió; per aquest cas vid. Soler en premsa.

7. Per a l'ècfrasi nocional, més habitual a l'Edat Mitjana, vid. Barbetti 2OII, 7, i també Pimentel 2OOI, II5.

8. Vid. en apèndix, la descripció de l'Arbre dels començaments de medicina del qual és extreta la frase. Vid. la nota $5^{\mathrm{I}}$ per al significat d' oir' i 'oïment'.

9. Vid., a continuació, la descripció de la Figura A de l'Art demostrativa: "segons que apar en lo començament de la Art". Vid. també les indicacions "ut apparet”, "prout apparet” o "ut in ipsa apparet” al Liber propositionum secundum Artem demonstrativam compilatus (Salzinger-Wolff ed. I722: viii, 2 (504)), a l'Ars inveniendi particularia in universalibus (ibid., vii, I (453)) i a l'Ars compendiosa (Ottaviano I930: I05, IO7 i Io8). 
La primera figura es circular, on està A en lo mig, segons que apar en lo comensament de la Art; e es la figura conposta de $\cdot x v j$. cambres avens linyes de la $\cdot j \cdot{ }^{\text {a }}$ cambra a altra, a significar que totes les cambres an conveniència e que en re no $\cdot s$ contrariejen.

En aquelles cambres son escrites $\cdot x v j \cdot$ dignitatz, les quals entenem esser en Deu, so es assaber: bonea, granea, eternitat, poder, saviea, amor, vertut, veritat, gloria, perfecció, justicia, larguea, simplicitat, noblea, misericordia, senyoria. (Galmés ed. I932: 7)
La primera figura es de A, e aquesta figura conté en si nou principis, ço es a saber bonesa, granesa e los altres, e hi ha nou letres, ço es a saber B, C e les altres, E aquesta figura es dita circular, per ço car lo subjet és mudat en predicat e lo predicat en subjet, així com dir bonesa es gran, granesa es bona, e enaixí dels altres. En aquesta figura encerca l'artista natural conjunció entre subjet e predicat, e disposició e proporció per ço que a fer conclusió puixa trobar mitjà. (Bonner ed. I989: I, 537)

Els conceptes del primer text són qualificats com a “dignitatz, les quals entenem esser en Deu" (i de fet en l'Alfabet de l'Art demostrativa es precisa que "A és Deu”), mentre al segon són "principis" (no es parla per res de la divinitat, ni es diu enlloc què vol dir la lletra A). També en el primer cas s'explica que les línies que connecten els conceptes signifiquen la conveniència (és a dir, la concordança) entre les dignitats, mentre que al segon no hi ha línies, i la circularitat de la figura s'explica en termes completament diferents: els de la predicació lògica. ${ }^{\text {io }}$ En suma, la informació que proporciona la descripció ecfràstica constitueix un resum d'alguns dels canvis més rellevants entre les dues etapes de l'Art.

Als Començaments de medicina (c. I274-83) trobem un cas extraordinari de combinació d'un discurs descriptiu molt detallat i precís amb una representació gràfica complexa de l'Arbre que organitza el desenvolupament de l'obra i que és absolutament imprescindible per seguir el text. Tota la primera distinció de l'obra és dedicada a descriure la morfologia, el funcionament i la intenció d’aquesta figura. En apèndix reproduïm la minuciosa descripció que Llull ofereix d'aquesta figura.

Dels Començaments de medicina hem conservat tres testimonis catalans i dinou de llatins, quatre dels quals són fragmentaris. No tots reprodueixen la figura de l'Arbre, encara que aquesta sigui

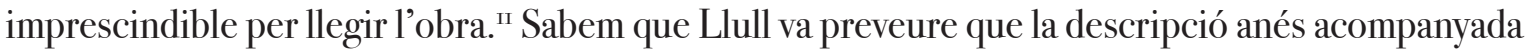
de la representació gràfica perquè hem conservat un manuscrit copiat per Guillem Pagès, l'escrivà que més estretament va treballar amb Llull mateix i durant més anys, on hi ha un dibuix de l'Arbre que ocupa un bifoli sencer de pergamí de dimensions notables. ${ }^{12}$ Tanmateix, entre els testimonis que sí que transmeten la figura, la varietat de formes amb què es dibuixa és considerable. Prenguem-ne dues mostres:

IO. A tots dos es diu que la figura és circular, però a la segona s’explica per què ho és: "aquesta figura és dita circular, per ço car ...”. Per a aquests canvis en la Figura A entre l'etapa quaternària i la ternària de l'Art, vid. Bonner 20I2: I05I3.

II. Per exemple, falta en un dels manuscrits catalans, el conservat a Milà, Ambrosiana, I IIz Sup., del pas del s. XIV al XV (als folis I25V-I26r hi ha un esbós inacabat, força maldestre, de l’Arbre); i tampoc no hi és en el que hi ha a Fermo, Biblioteca Comunale, ms. I9, que transmet la versió llatina de l'obra i que cal datar en un moment tan reculat com I280I3OO.

I2. Guillem Pagès, va copiar manuscrits lul-lians almenys entre ı274 i r3or; n’hem conservat sis, alguns dels quals amb traces o indicis d'intervencions personals de Ramon, vid. Soler 20o6a. Els Començaments de medicina que va dur a terme Pagès es conserven al manuscrit Dhún Muire B95 del University College de Dublín, que amida 326 x 220 mm.; l'Arbre que conté presenta algunes peculiaritats que aconsellen deixar-lo de banda en aquesta ocasió; ens n'ocuparem en un treball futur. 


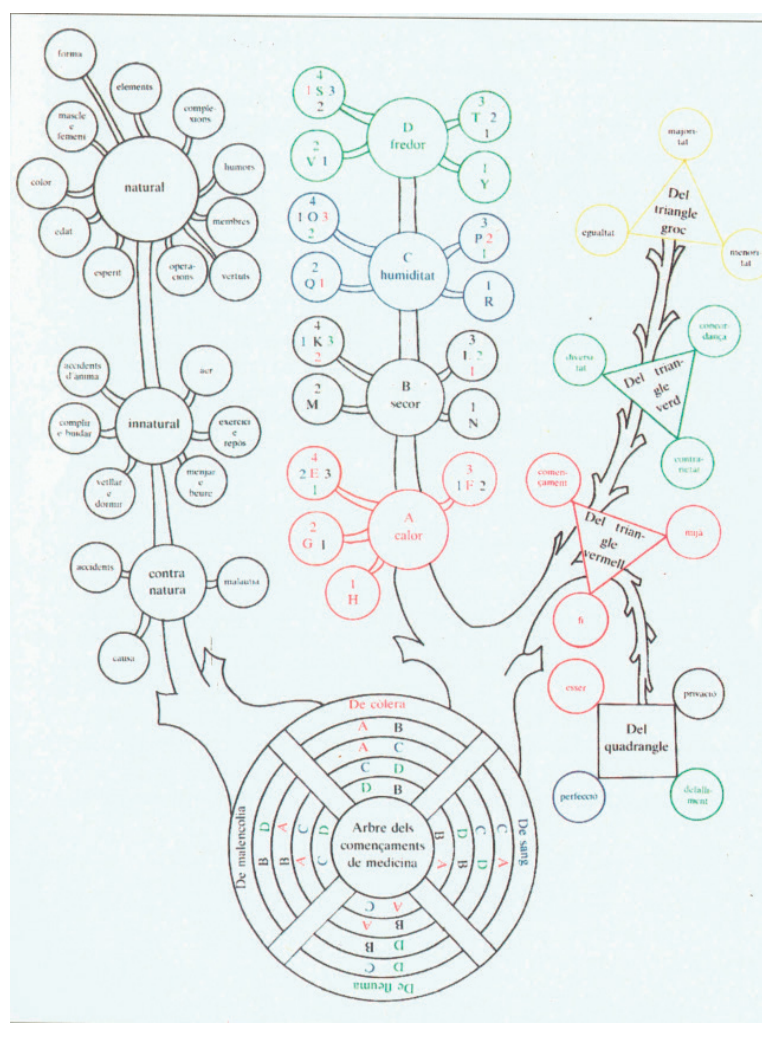

4. Arbre dels Començaments de medicina.

Reproduït de Badia ed. 2002, 4I i Bonner ed. I989, 2, 4IO, adaptada de Palma, Bibl. Publ. Io29, f. 23v

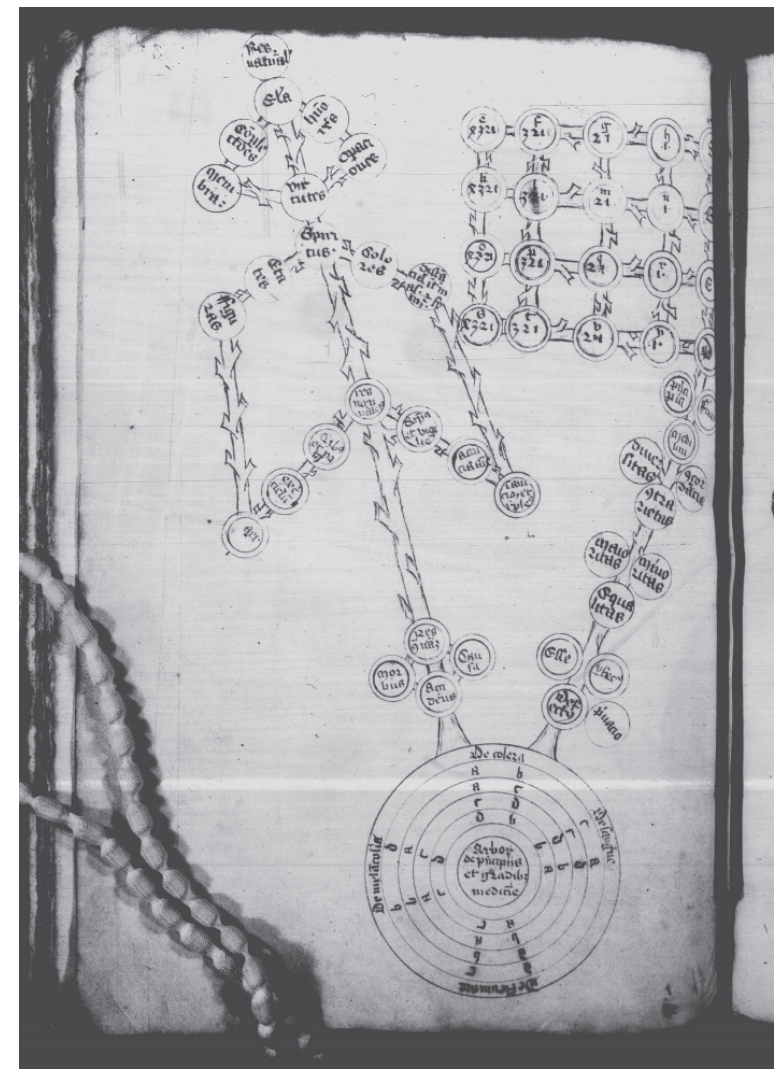

5. Oxford, Corpus Christi College 247, f. $5^{8 \mathrm{v}}$ (C) Corpus Christi College http://tinyurl.com/jj6svqk

Les arrels d'aquest arbre no presenten, com podria semblar, una roda giratòria (una volvelle), sinó quatre taules que mostren com es mesclen els humors (còlera, sang, fleuma i malencolia) en la producció de febres (Bonner ed. I989: 2, 4I2 i 47I ss.). A la part superior de l'arbre, la branca de l'esquerra és un esquema que il-lustra arbòriament les tres divisions de la medicina tradicional. La branca de la dreta és una versió reduïda de l’Art, amb tres triangles de la Figura T i un quadrat de la Figura X; es tracta purament d'una selecció de les figures de l'Art quaternària. La tercera branca és la que a la il-lustració 4 ocupa un lloc central, i que, a la il-lustració 5, apareix de forma tabular a la part superior de la branca dreta. Es tracta de dues maneres de representar la relació entre les quatre qualitats elementals i els seus possibles quatre graus d'intensitat. El primer problema que havia de plantejar-se l'il.lustrador era com distribuir els diversos elements que conformen l'Arbre en l'espai de què disposava, de manera que el resultat fos clar i ordenat. La descripció que en fa Llull en el text és molt detallada però les plasmacions gràfiques que es poden donar a partir del text escrit són molt diverses. Sigui com sigui, Llull tenia molt clara la importància que el lector disposés de la imatge gràfica de l’Arbre i ho recomana expressament al final de la descripció: "Qui aquesta art vol entendre ni saber, a ssaber li cové l'alfabet damunt dit, et cové que les flors de l'arbre translat en altres flors movables et entalades, per tal que pusca demostrativament mesclar et formar et egualar et crexer o minvar les unes ab les altres".

És important adonar-se que aquesta recomanació de construir-se una figura mòbil per a ús propi, a partir de la figura que s'acaba de descriure, constitueix una invitació perquè el lector s'atreveixi a desenvolupar un treball autònom amb aquest recurs gràfic i amb les possibilitats que ofereix. 


\section{La construcció mental de la imatge: ècfrasi nocional}

Al darrer capítol del Liber de fine, Llull fa un veritable catàleg de les obres seves que considera imprescindibles per a la missió. Després d'un breu paràgraf on parla de l'Art general -sense mencionar cap títol específic-, hi ha una segona part intitulada "De viginti artibus specialibus", encapçalada per les tres obres els títols de les quals comencen amb la paraula "arbor", i no "liber" com les disset següents (Madre ed. I98I: 285-86). Són l'Arbre de ciència, l'Arbre de filosofia desiderat i l'Arbre de filosofia d'amor, obres en les quals l'ècfrasi té un paper fonamental en la presentació de l'estructura arbòria. En aquest apartat tractarem del primer i del darrer llibre, mentre que en l'apartat següent ho farem de l'Arbre de filosofia desiderat.

L'Arbre de ciència no és només l'obra que presenta més detalladament la visió lul-liana del món, sinó també la que més desenvolupa la figuració ecfràstica en absència de qualsevol imatge. L'arbre -en realitat els arbres- que dóna nom a l'obra té una estructura complexa que només es pot explicar recollint una selecció bastant extensa de les descripcions que Llull fa al llarg del llibre.

L'obra comença amb un diàleg entre Ramon i un monjo en un locus amoenus entorn a un "bell arbre". Ramon es plany del poc cas que li fan, sobretot a la cort de Roma. El monjo li suggereix que, per ser més conegut i escoltat, escrigui una obra que ajudi a entendre tant la seva Art general com les altres ciències. A la fi Ramon accedeix a aquests requeriments i diu que prendrà com a base l'arbre que tenen davant:

Sènyer En Monge, jo pens en ço que significa aquest citroner, ${ }^{13}$ car totes quantes coses són, en ell són significades; e per açò som en volentat que faça lo libre de què vos me pregats, resebent los significats que aquest arbre me significa, en set coses, ço és a saber: per rails, e per lo tronc, ço és a saber la cana de l'arbre, e per les branques, e per los rams, e per les fulles, e per les flors, e per lo fruit. E per totes aquestes set coses propòs a tenir lo procés d'aquest libre. (Llull ı957-60: I, 556)

Aquest breu passatge explica amb força precisió el procés pel qual Ramon ha interioritzat el significat del llimoner que ha contemplat (pensa en l'arbre, s'adona que és un signe de tot el que existeix i en rep els significats) i que li ha permès concebre la figura arbòria que després descriurà. L'Arbre de ciència consegüent no serà una pura imitació del llimoner original, sinó una representació d'allò que significa. ${ }^{5}$

Segueix un breu apartat on enumera les setze parts que tindrà l'obra, ${ }^{16} \mathrm{i}$ immediatament comença

I3. La versió llatina de l'obra parla d'un genèric “arborem”, potser perquè un llimoner era un arbre força desconegut per a un traductor del nord; segles més tard Goethe, a Els anys d'aprenentatge de Wilhelm Meister, encara podia descriure Itàlia com un país exòtic "wo die Zitronen blumen”.

I4. Aquesta descripció de l'arbre general és l'única que dóna Llull, però atès que només enumera les seves set parts, no pot ser considerada realment una descripció, és a dir un exemple d'ècfrasi. Per contra, la descripció transcrita a continuación de l’Arbre elemental, model dels altres arbres, sí que és ecfràstica.

I5. "Probably the most representative of medieval aesthetic thought was Aquinas' injunction that: «art imitates nature in its operation». This assertion is significant to the shape that ekphrasis takes in the Middle Ages because it ushers art out of the realm of mimesis: art does not imitate nature; it imitates the way that nature works, in essence the processes of nature. Art is not about copying what is seen". (Barbetti 20II: 8).

I6. L’Arbre elemental (I) descriu la naturalesa de la matèria; l’Arbre vegetal (2) analitza les funcions vitals de l'alimentació i de la reproducció; l’Arbre sensual (3) presenta els sentits dels animals i dels homes; l’Arbre imaginal (4) investiga la funció representativa a través de les dades dels sentits; l’Arbre humanal (5) desplega les facultats superiors de l'ànima racional; l’Arbre moral (6) és un tractat sobre les virtuts i els vicis; l’Arbre imperial (7) estudia els estaments socials, el dret i les formes de govern; l’Arbre apostolical (8) analitza l'estructura de l'Església i el dret canònic. L'Arbre celestial (9) explica què són les esferes, el zodíac i els planetes des de la perspectiva d'un cosmos geocèntric, presidit per la divinitat infinita. Els cinc arbres restants, que tracten d'éssers purament espirituals, són: l’Arbre angelical 
la primera:

\section{De l'Arbre elemental}

Aquest arbre és departit en set parts: la primera és de les sues rails, la segona del seu tronc, la terça de les sues branques, la quarta és dels seus rams, la quinta és de les sues fulles, la sexta és de les sues flors, la setena és del seu fruit.

Per les sues rails entenem los començaments de l'Art general, ço és a saber, bonea, granea, duració, poder, saviesa, volentat, virtut, veritat, glòria, diferència, concordança, contrarietat, començament, mijà, fi, majoritat, egualtat e minoritat.

Per lo tronc entenem l'ajustament de tots aquests començaments corporals, d'on se segueix lo cors confús qui és apellat caos, e qui compleix tot l'espai qui és dejús la luna, e en qui són sembrades les espècies de les coses e les disposicions e.ls hàbits d'aquelles, en tant que ell hi és substància confusa subjacent als accidents de les coses elementades.

Per les branques entenem los quatre elements simples, ço és a saber, lo foc, l’àer, l'aigua e la terra, qui són substàncies de les coses elementades en elles sustentades, e elles són insensibles e incorrompables en quant són simples.

Per los rams entenem les quatre masses qui són los quatre elements composts e sensibles, ço és saber, lo foc qui és en la flama, e l'àer mogut qui és enfre nós e la luna, e l'aigua de la mar e dels flums e de les fonts, e la terra en què habitam e en la qual som sostinguts. E aquests són membres de l'Arbre elemental.

Per les fulles entenem los accidents de les coses corporals corrompables, així com quantitat, qualitat e.ls altres.

Per les flors entenem los estruments de les coses, així com la mà, qui és estrument a obrar, e lo peu a anar.

Per lo fruit entenem los elementats, així com la pera e la poma, e l’home e·l leó, e.l peix e l'aucell e l'aur e l'argent. (Llull I957-60: I, 556-57)

El capítol segueix amb desenvolupaments extensos d'aquests set components. A continuació ve el segon arbre, i Llull remarca, amb una certa insistència, que no es pot separar del primer (subratllem en cursiva paraules estructuralment significatives):

\section{De l'Arbre vegetal}

Aquest arbre és departit en set parts, ço és a saber, en rails, tronc, branques, rams, fulles, flors e fruits. E és arbre doble en quant és diferència d'ell e de l'arbre elemental, en lo qual és empeltat per creació, ço és a dir, que Déus ha creada la potència vegetativa en ell e d’ell, així com Déus, qui creà home en la terra e del lim de la terra; e per açò són los individuats cajús elementats e vegetats. On, com aquest arbre sia doble, cové que.l menem doblement per nostre enteniment, per ço que mills d'ell coneixença puscam haver.

De les rails de l'Arbre vegetal

Les rails de l’Arbre vegetal són bonea, granea, duració e les altres que dit havem en l’Arbre

(Іо); l’Arbre eviternal (ІІ), que parla del paradís i de l'infern; l’Arbre maternal (І2), sobre la verge Maria; l’Arbre cristianal (I3), sobre el Déu Fill encarnat, i l’Arbre divinal (I4), que aborda la teologia. Els dos darrers tenen una funció complementària: són l'Arbre exemplifical (I5) i l’Arbre qüestional (I6). L'Exemplifical proporciona narracions, proverbis o semblances relacionats amb el contingut dels arbres inicials, mentre que el Qüestional, que pràcticament duplica l'extensió de l'obra, replanteja tota la matèria en forma de preguntes, algunes de les quals porten respostes específiques molt aclaridores, mentre que d'altres remeten al lloc corresponent de la part anterior. 
elemental. E cascuna d'aquestes rails és doble en quant conté en si natura elemental e vegetal, general e especial; general, ço és elemental; especial és la vegetal. E ensems són una rail ajustada d'abdues natures, qui és bona sots raó de bontat; e la natura vegetal transubstancieja en sa espècie l'elemental, enaixí com l'olivier empeltat en l'ullastre. E totes ensems les rails són línies qui s’han al tronc vegetal de l'arbre, al qual donen lurs condicions e lurs natures. (Llull I957-6o: I, 590)

Les branques, rams, fulles, flors i fruit de l'Arbre vegetal segueixen la mateixa tònica, explicant la seva naturalesa doble, al mateix temps que es demostra com el nou material està connectat a la part equivalent del primer arbre. Com a exemple, podem veure com les branques de l'Arbre vegetal estan relacionades amb les de l'Arbre elemental, on s'han presentat (com hem vist més amunt) els quatre elements.

De les branques de l'Arbre vegetal

Les branques de l’Arbre vegetal són dobles, car les unes són de la natura elemental e les altres de la vegetal. E les branques vegetals són quatre, ço és a saber, la potència apetitiva, retentiva, digestiva e expulsiva. [...]

\section{De l'apetitiva}

La potència apetitiva és raó per la qual les unes parts vegetades han apetit a les altres; e en aquest apetit està l'apetit de los vegetals; e per açò és l'apetit doble e compost, així com lo pomer, qui ha apetit a la pluja, per ço que ab la fredor de l'aigua pusca multiplicar sa fredor, e ha apetit al dia, per ço car ab la calor del sol pusca multiplicar sa calor; e açò mateix de l'apetit que ha a la terra e a l'àer. (Llull 1957-60: I, 59I)

Al tercer arbre es mostra com continua el procés d'agregació:

\section{De l'Arbre sensual}

Aquest arbre és dels animals, e és departit en set parts, segons que en ell se conté. E és tríplex, ço és a saber, de l'elementativa potència, e de la vegetativa, e de la sensitiva. On, enaixí com un arbre qui fos de tres espècies, així com empeltat pomer en perer e preseguer en pomer, serien en un arbre totes tres les espècies, enaixí empeltada la vegetativa en l'elementativa, e la sensitiva empeltada en la vegetativa, retén un arbre totes tres les potències. Emperò, d'aitant és la diferència, que.l tronc de l'arbre qui seria del pomer, preseguer e perer, seria de quantitats discretes, e aquest arbre és de quantitats contínues estants los uns arbres en los altres. (Llull I957-60: I, 594)

En els passatges ara citats es veu clarament que els setze arbres de l'obra s'aglutinen i formen un sol arbre, que és l'Arbre de ciència. ${ }^{17}$ Si se’ns permet la comparació, el procés té una semblança amb la moderna impressió $3 \mathrm{D}$, en què es forma un objecte tridimensional (que pot ser d'una gran complexitat) amb la superposició de successives capes finíssimes de material. O, com explica Llull, es tracta d'una mena d'empelt en què dos o més arbres s'uneixen en un de sol; un que, però, té "quantitats contínues", és a dir, en què desapareixen les fronteres entre un subarbre i l'altre per formar un sol Arbre de ciència. Això és d'importància cabdal, perquè mostra el que Llull vol fer amb aquesta obra: no vol desplegar una enciclopèdia on es presenti ordenadament la diversitat del món, sinó que - tot al contrari- vol mostrar la unitat indissoluble de la realitat plasmada en un sol arbre

I7. Per a més detalls sobre l'organització de l'obra vid. Bonner 2002. 
que al mateix temps és múltiple, o "múltiplex" com sembla que Llull hauria preferit dir. ${ }^{18}$

En aquesta concepció d'unitat en la multiplicitat, es produeix de manera natural una graella on cada component d'un arbre -per exemple les branques de l'Arbre vegetal, com hem comentat abans- es relaciona verticalment amb els sis altres components d'aquell arbre, des de les arrels fins al fruit, al mateix temps que es connecta horitzontalment amb els components corresponents dels altres quinze arbres - amb les branques del altres quinze arbres, en aquest cas. Així que la descripció ecfràstica construeix una imatge mental de l'ontologia lul-liana, un cos unificat amb totes les seves parts interrelacionades d'una manera ordenada.

Com explica Mary Carruthers, amb una descripció com aquesta la figura sovint actua com una mena d'índex ("a table of contents") de tota l'obra. ${ }^{19}$ Aquí, de fet, el llibre es divideix en setze arbres, cada un dels quals es divideix en raïls, tronc, branques, rams, fulles, flors e fruits; es tracta, doncs, d'una figura que el lector sempre ha de tenir present.

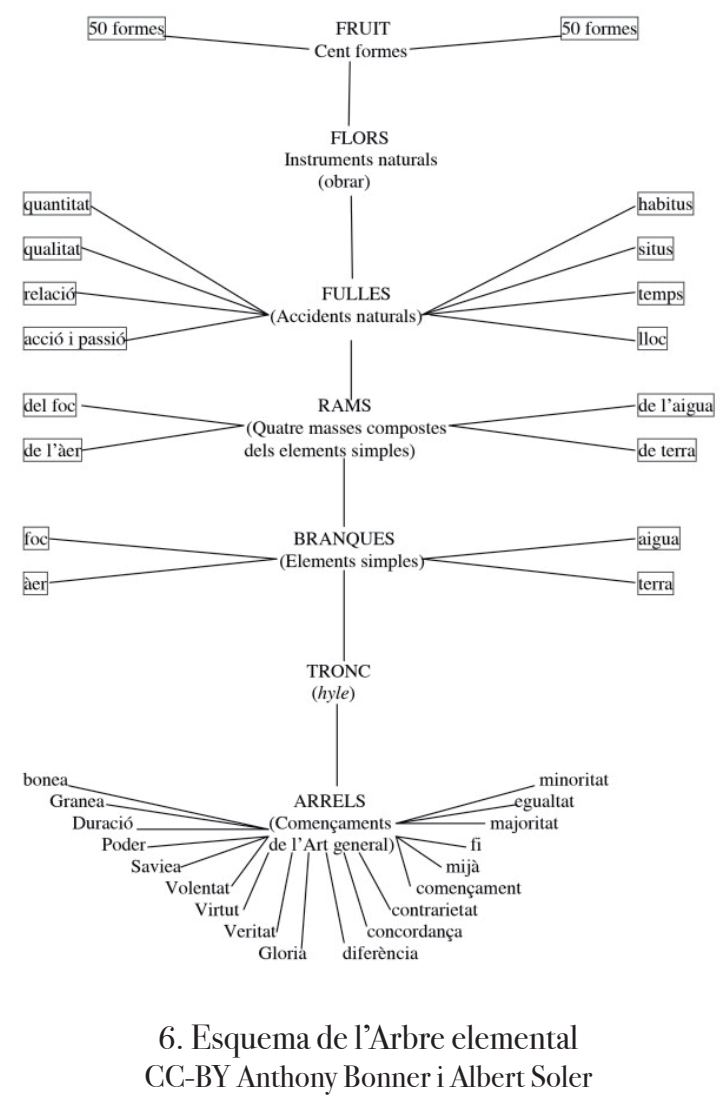

L'ècfrasi de l'Arbre de ciència, per molt complicada que pugui semblar, desenvolupada textualment i de manera acuradament ordenada com fa Llull, produeix una imatge mental que el lector pot assimilar amb relativa facilitat. D’altra banda, adonem-nos que es tracta d'una imatge impossible de plasmar en un dibuix sobre paper. L'aglutinació dels setze subarbres crea un model pluridimensional (o "múltiplex") impossible de representar. Si hom volgués dibuixar un dels

I8. Vid. el "tríplex" de la citació més amunt.

I9. Carruthers 2006: 288-89. De fet, l'extensa taula de rúbriques que presenta l'únic manuscrit català complet de l'Arbre de ciència (Ambrosiana D 535 Inf) actua alhora com una taula de continguts i com una veritable descripció ecfràstica esquemàtica de la figura de l’Arbre. 
subarbres tot sol, la imatge que resultaria segurament seria semblant a la de la il·lustració 6 , amb fulles, flors i fruits que surten directament del tronc; i, en qualsevol cas, seria molt difícil trobar la manera d'expressar que cada un d'aquests nivells brota de l'anterior. ${ }^{20}$

Això explica per què, sens dubte per voluntat de l'autor, l'obra no conté cap representació de cap arbre en cap manuscrit; ${ }^{21}$ només apareixen, i de manera esquemàtica, a les edicions impreses de Barcelona, I5O5 i Lió, I5 $5 .^{22}$ El lector modern que s'hagi habituat a edicions que reprodueixen algun d'aquests gravats dels primers impresos, podria pensar que la descripció de l'Arbre es refereix a una figura gràfica existent en el llibre; que és una ècfrasi referencial, doncs. En realitat es tracta d'una ècfrasi nocional, d'un Arbre que per les seves característiques només es pot concebre mentalment.

Només un parell d'anys després de l'Arbre de ciència, Llull va escriure l'Arbre de filosofia d'amor (ı298), on desenvolupa una versió simplificada -amb només un arbre simple, en comptes d'un arbre múltiple format per setze arbres- de l'estructura de l'obra anterior. La descripció de l'Arbre d'amor es troba en vuit petits fragments repartits per l'obra. El primer és un de general a la introducció on es fa referència al model de l'Arbre de ciència: “departit en ·vij· parts, que son: rails, tronc, branques, rams, fules, flor e fruyts; e aquesta divisió consirà Ramon segons la division del Arbre de sciencia que fet havia" (Galmés ed. 1935: 72).

Els altres passatges es troben al començament de cada una de les set parts en les quals l'obra és dividida. El primer diu:

Remembrà Ramon la Art amativa que feta avia, e près los ·xviij· començaments d'aquela, e aquels apel-là “rails" d'aquest Arbre d'amor, les quals rails son: bonea, granea, duració, poder, saviea, volentat, virtut, veritat, gloria, differencia, concordancia, contrarietat, comensament, mitjà, fi, majoritat, egaltat e menoritat. (Galmés ed. 1935: 73)

Després d'aquest primer esglaó dels divuit principis de l'Art ternària, els altres sis esglaons només despleguen tres conceptes cada un. Per exemple al següent s'explica que "Lo tronc de l'Arbre d'amor es departit en tres parts, ço es a saber, en forma d'amor, e en materia d'amor, e en la conjunció d'amdós" (ibid., 86). I així successivament, fins al darrer: "Fruyt d'amor es departit en .iij- parts: una part es Deu, altra es la sua obra, tersa es benauyransa" (ibid., 205).

L'arbre que descriu aquesta petita col-lecció de texts es pot dibuixar fâcilment (vid. fig. 7), tant com l'Arbre elemental de la figura 6 , i seria una representació equivalent a la imatge mental que el lector es faria -i que Llull esperava que es fes. Tanmateix, només hi ha dos manuscrits que hagin intentat representar l’Arbre d'amor, amb un resultat botànicament curiós (vid. figures 8 i 9). En lloc del nus central amb el nom de cada part que hem posat a l'esquema de la figura 7 , hom ha dibuixat

20. Vid. Cruz Hernández 1977: I27-42, per a un intent meritori de dibuixar tots setze arbres.

2I. Això mateix assenyalen Salonius-Worm 20I4: 5. L'únic manuscrit que té voluntat de representar l'Arbre de ciència és el català de Milà, Ambrosiana, D. 535 Inf., f. 37v, del segle XV, reproduït a Villalba ed. 2OoO, I, frontispici. A banda de ser una bella miniatura, la informació que ofereix és dràsticament reduïda: les divuit arrels no són dibuixades gràficament, el tronc no està rotulat de manera que indiqui les diverses funcions que té, les setze branques que segueixen les setze divisions del llibre están retolades "Del arbre elemental”, "Del arbre vegetal”, "Del arbre sensual”, etc., cada una de les quals amb la mateixa successió de cinc fulles, una flor i un fruit, amb la mateixa retolació de "rayls", "tronc" (o "trunc"), etc. repetida a cada branca. El resultat és una il-lustració molt esquemàtica, sense valor diagramàtic. Dels dibuixos que acompanyen cada capítol de Vaticà Lat., 3468 i de Munic, Clm. IO498, repetits a cada apartat de l'edició de Villalba ed. 2000, només se’n pot dir que són igualment il·lustracions decoratives sense cap valor diagramàtic.

22. No a la primera de Barcelona (I485). Totes aquestes il-lustracions estan reproduïdes a l'edició llatina de Villalba ed. 2000 , intercalades al text amb altres de modernes. 
branques amb rètols (començant per baix i d'esquerra a dreta): "rails", "trunc", "branques", "rams", "fules", "flors" i "fruit", de les quals broten els tres conceptes de les diverses parts de l'obra. ${ }^{23}$ Així que, en darrer terme, l'ècfrasi de l'Arbre de filosofia d'amor és tan nocional com la de l'Arbre de ciència.

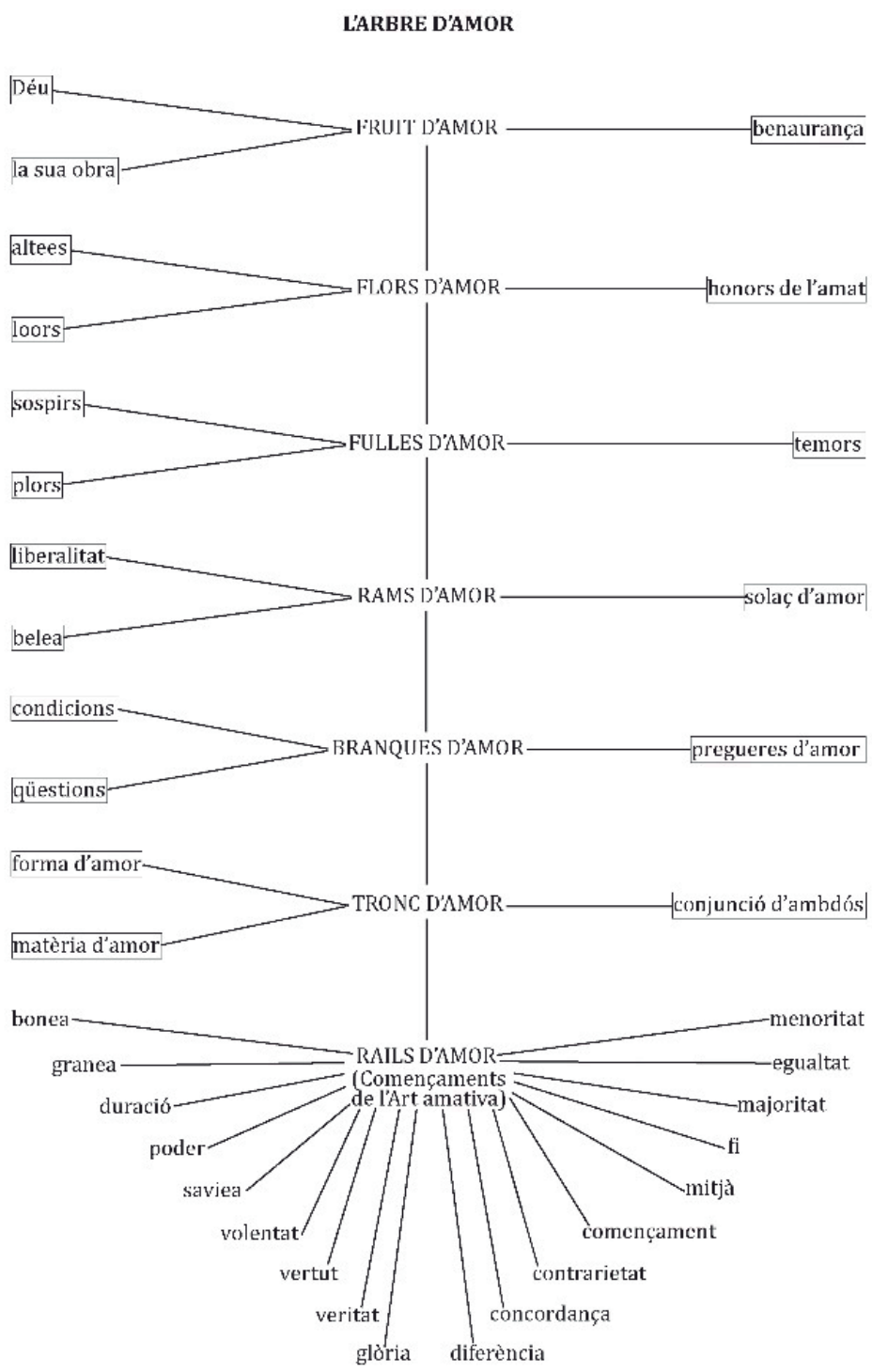

7. Esquema de l'Arbre d'amor

CG-BY Anthony Bonner i Albert Soler

23. Cal ressaltar que les dues miniatures (figs. 8 i 9) són tan similars que semblen copiades l'una de l'altra, tot i que l'una apareix en un ms. de la versió catalana de l'obra i l'altra en un ms. de la versió llatina. A totes dues manquen les arrels de l'arbre, presenten els personatges de Ramon i Filosofia d'amor (identificats amb rètols) intercanviant un llibre, ella davant un banc (a la de Kues, sembla que asseguda), assenyalant amb la mà dreta apuntant cap amunt tot l'aparat de l'arbre, mentre que Ramon escolta, recolzat en un bastó. Les úniques diferències són la franja a la part superior del ms. de la Sapiència, (per a la qual vid. Soler 20o6b: IO-I7), i, al ms. de Kues, la presència d'un rètol al tronc de l'arbre que diu "Arbor philosophie amoris". 


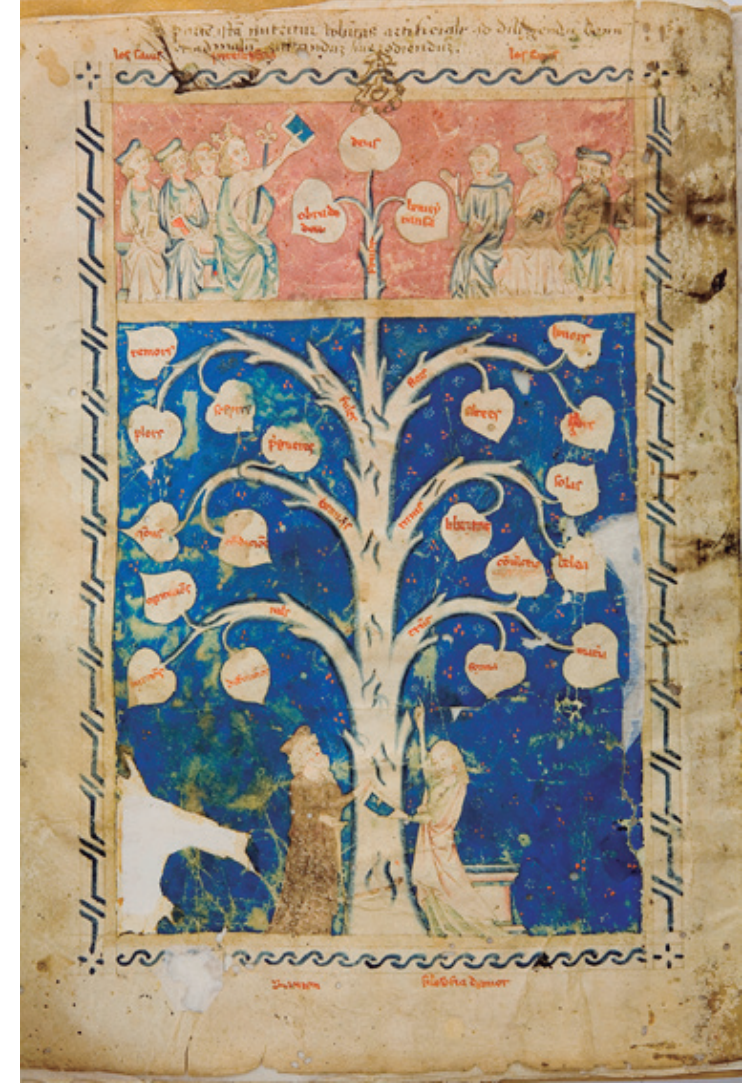

8. Palma, Sapiència F-I29, f. Iv

(C) Biblioteca Diocesana de Mallorca http://tinyurl.com/jedtgyw

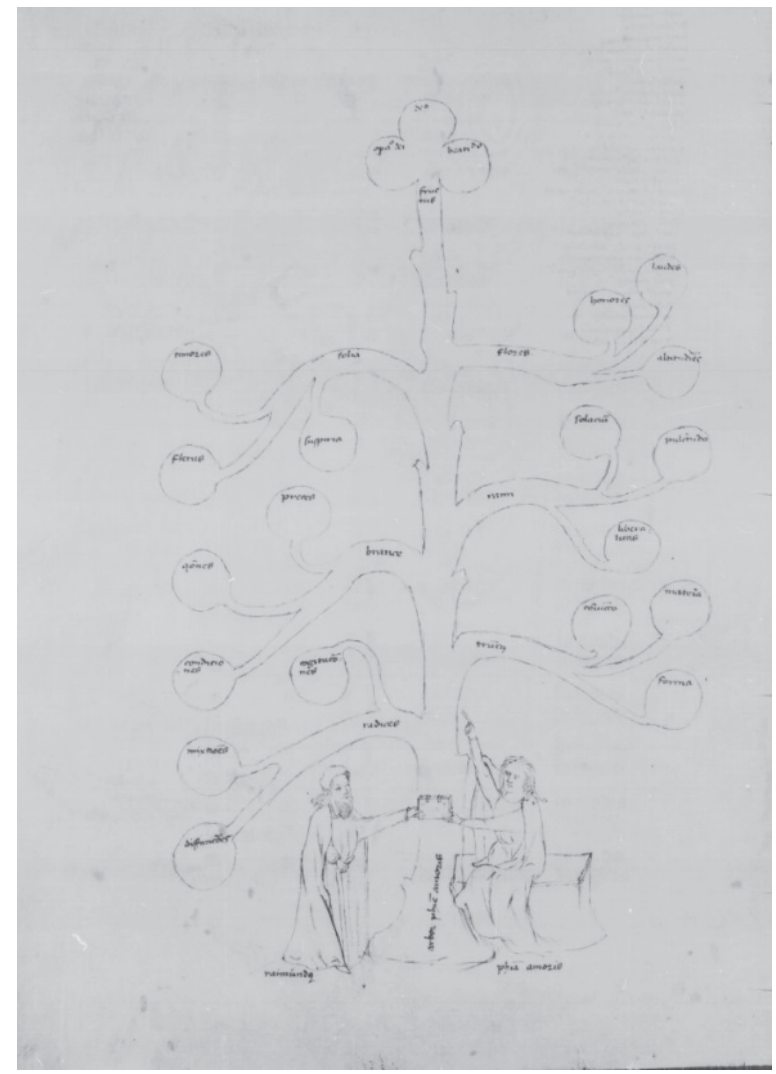

9. Bernkastel-Kues, Hosp, 83 , f. $3^{\mathrm{v}}$

(c) St. Nikolaus-Hospital http://tinyurl.com/jtllnhj

\section{${ }_{3}$ Un desenvolupament peculiar del discurs ecfràstic}

$\mathrm{L}$ a relació que s'estableix entre descripció i figures de la tercera de les "Arts especials", l'Arbre de filosofia desiderat (I294) és peculiar, encara que es tracti, com als exemples al principi d'aquest treball, d'un cas d'ècfrasi referencial.

Aquesta obra forma part d'una sèrie que Ramon va adreçar al seu fill, juntament amb la Doctrina pueril (c. 1274-76) i el Llibre d'intenció (c. 1276-83). ${ }^{24}$ La matèria que s'exposa en totes tres presenta una gradació en la dificultat dels continguts: des de les beceroles del catecisme i de la instrucció cristiana, passant pel discerniment de les finalitats de tot el que existeix, fins arribar a aquesta versió reformulada de l'Art, en la qual Ramon sembla que vol proporcionar una base més purament filosòfica per impulsar el seu fill "a menbrar e conèxer Deu e amar, e a manifestar la santa fe cathòlica a aquels qui no la coneixen". A banda d'aquesta base, també introdueix mecanismes combinatoris nous, com veurem en descriure les figures.

24. Llull va tenir dos fills: Domingo i Magdalena. Encara que el motiu didàctic del pare que adreça un llibre instructiu al seu fill és darrere la Doctrina pueril i el Llibre d'intenció, no es pot negar que, a l'Arbre de filosofia desiderat, Ramon dóna alguns detalls personals que difícilment podrien ser elements d'una ficció; així, es lamenta del molt de temps que ha passat des que es van veure: "Gran temps ha, fil, que·t tramès lo Libre d'entenció, e car lonc temps ha que jo no·t he vist, no sé si d’aquel as reebuda utilitat” (Galmés ed. i933: 4I4); o com quan fa referència a la mort de la seva muller, Blanca Picany, i mare del seu fill: “Consira, fil, en .iij. maneres fi, so es a saber, fi que es de privació de les cozes que eren e no son, axí com la tua mare que sulia eser e es fenida ... (ibid, 4I5). 
Al'Arbre de filosofia desiderat trobem una peculiar forma de discurs ecfràstic, alhora referencial -hi haurà descripció de figures presents en el llibre-i nocional, atès que mitjançant l'exposició de l'obra es pretén que el lector es faci una construcció mental més completa que la figura de l'Arbre i que va més enllà de qualsevol representació gràfica. Llull va concebre aquesta obra acompanyada de dues il.lustracions: un arbre i una figura giratòria, una volvelle. Ho sabem, en primer lloc perquè el text hi fa al·lusió; ${ }^{25} \mathrm{i}$ en segon lloc perquè els manuscrits efectivament les han transmeses. ${ }^{26} \mathrm{Com}$ en el cas de l'Arbre dels Començaments de medicina, però, les materialitzacions d'aquestes figures prenen formes diverses malgrat que l'autor en fa una descripció detallada.

La descripció de les dues figures es distribueix en cinc passatges, que hem marcat amb una xifra entre claudàtors. Hem assenyalat amb un [I] els dos pasatges en què es tracta de les parts subterrànies de l'arbre; amb un [2], el passatge en què s'explica l'estructura de l'arbre mateix, amb les nou parelles de conceptes que constitueixen les seves "rames flors"; ${ }^{27}$ amb un [3] hem marcat els dos passatges en què es descriu la volvelle, que proporciona les dues sèries de nou lletres contingudes en els seus quatre cercles; a [4] es presenten les nou tríades de "comensaments" (és a dir, principis) que constitueixen "les flors" de l'arbre; i a [5] s'assignen lletres de l'alfabet als conceptes de [4] i [2].

En la primera part affiguram aquest Arbre segons aquesta manera, so es a saber, que [I] les rails son de cahos confús conpost mesclat de cozes espirituals e corporals, e per assò son tres les sues rails: la primera es espiritual, la segona corporal, la tersa es lo mesclament d'amdues, so es assaber, lo cahos confús que dit avem; [2] e en la cana del arbre posam ens ·ix· vegades, e assò fem car dejús ens poden esser considerades totes cozes, con sia so que ens sia lo pus general vocable que hom puixa nomenar; e conciram ens en ·ix. maneres, car en aqueles poden esser considerades totes cozes.

Les rames flors de aquest arbre son: ens qui es Deus e ens qui no es Deus [= creatura], ens reyal e ens fantàstic, ens qui es genus ens qui es specia, ens movent ens movible, ens unitat ens pluralitat, ens abstractu ens concret, ens intens ens extens, ens qui es semblança ens qui es dessamblansa, ens qui es generació ens qui es corrupció.

[I] Aquest arbre es plantat en memòria enteniment e volentat, so es assaber, en les obres d'aquestes potencies; car segons lo seu procés porà la memòria remembrar les cozes passades, e l'enteniment entendre les cozes veres, e la volentat amar les cozes bones e desamar les males. [...]

L'aiga ab que tu deus regar aquest Arbre ix de tres fons, so es assaber, fe speransa e karitat; e d'aquest flum que ix d'aquestes tres fons, ixen -iiij- rius, los quals son justicia prudència fortitudo e tempransa; e tu deus regar aquest arbre $\cdot \mathrm{X} \cdot$ vegades, segons que son los $\cdot \mathrm{X} \cdot$ manamens, e deus donar del seu fruit ·vij· vegades segons los ·vij· dons de sant Spirit.

De la segona part

25. En la descripció de la figura circular, llegim “segons que en ela apar [...] segons que en él apar” (Galmés ed. I933: 406-O7), en clara referència a la il.lustració.

26. La versió catalana és conservada completa en un sol manuscrit de començament del segle XIV (l’Hisp. 6o de la Bayerische Staatsbibliothek de Munic), i en dos altres de fragmentaris. La versió llatina és conservada en 24 manuscrits (alguns, però, només en transmeten fragments), dels quals dos són també d’inici del segle xiv: el lat. i6ıı6 de la Nationale de França, i el Ricc. 337 de Florència; el primer d'aquests té una autoritat inqüestionable perquè va pertànyer a Tomàs Le Myésier, principal deixeble de Ramon a París.

27. El terme "rames flors" sembla una creació calculadament ambigua per designar les parts de l'arbre que hi ha entre el tronc i les flors, atès que en la descripció no hi ha cap menció explícita de parts com fulles, rams o branques. En el ms. parisenc base de l'edició llatina de Compagno-Roth ed. 2OII, el terme és traduït per "flores", però gairebé tots els altres mss. (I7 en total) donen "rami et flores", com si no estiguessin segurs de com traduir la misteriosa denominació de "rames flors" de l’original català. 
[3] La figura circular contén en sí ·iiij· cercles: los ·iij· son movibles segons que en ela apar. En lo cercle subirà son escrites aquestes letres: b. c. d. e. f. g. h. i. k. Que fan -ix· cambres, segons que en él apar; e en lo cercle conseqüent ha ·ix. cambres en les quals son aquestes letres: 1. m. n. o. p. q. r. s. v. ${ }^{28} \mathrm{e}$ en l'altre conseqüent son les letres que son en lo cercle subirà, so es assaber b. c. d. e les altres; e en lo quart cercle ha ·ix. cambres en qui son les letres del segon cercle, so es assaber l. m. n. ${ }^{29} \mathrm{e}$ les altres.

[4] Los comensamens, so es a saber, les flors d'aquest arbre, son ·xxvij·, les quals son aquestes: bonea, differencia, potencia; granea, concordança, object; duració, contrarietat, memoria; poder, comensament, entenció; saviea, miyà, punt transendent; volentat, fi que es perfecció, buyt; vertut, majoritat, obra; veritat, egualtat, justicia; gloria, minoritat, orde.

$[5] \cdot b \cdot$ significa bontat e differencia e potencia; $\cdot c \cdot$ significa granea concordansa e object; $[\ldots] \cdot k$. significa gloria minoritat e orde.

Ens qui es Deus e ens qui no es Deu es significat per $\cdot 1 \cdot ;$ ens reyal e ens fantàstic per $\cdot m \cdot ;[\ldots]$ ens qui es generació e ens qui es corrupció per · $\cdot$ ·.$[\ldots]$

[3] Lo discurriment d'aquesta figura faràs, fil, volvent los uns cercles en los altres e formant les cambres d'aquesta figura, axí com aquesta cambra de b.l.c.m. (Galmés ed. 1933: 404-o8)

La visualització d'aquest text s'ha realitzat segons dos models presentats així en els dos còdexs llatins més antics de l'obra:

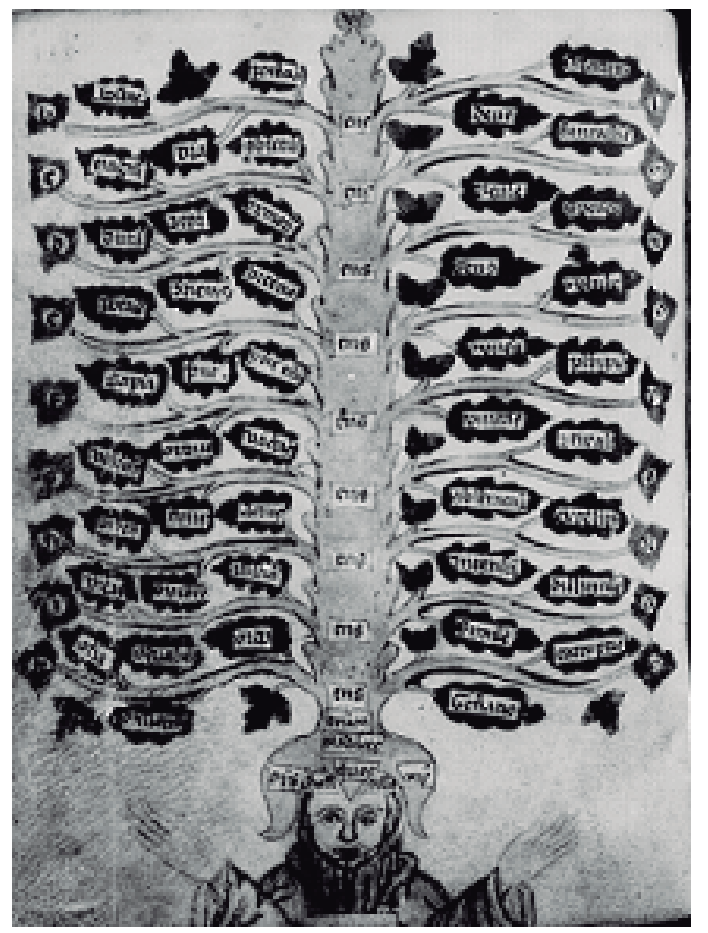

IO. Florència, Ricc. 337, f. 2IIV, (C) Biblioteca Riccardiana http://tinyurl.com/zb5xwxj

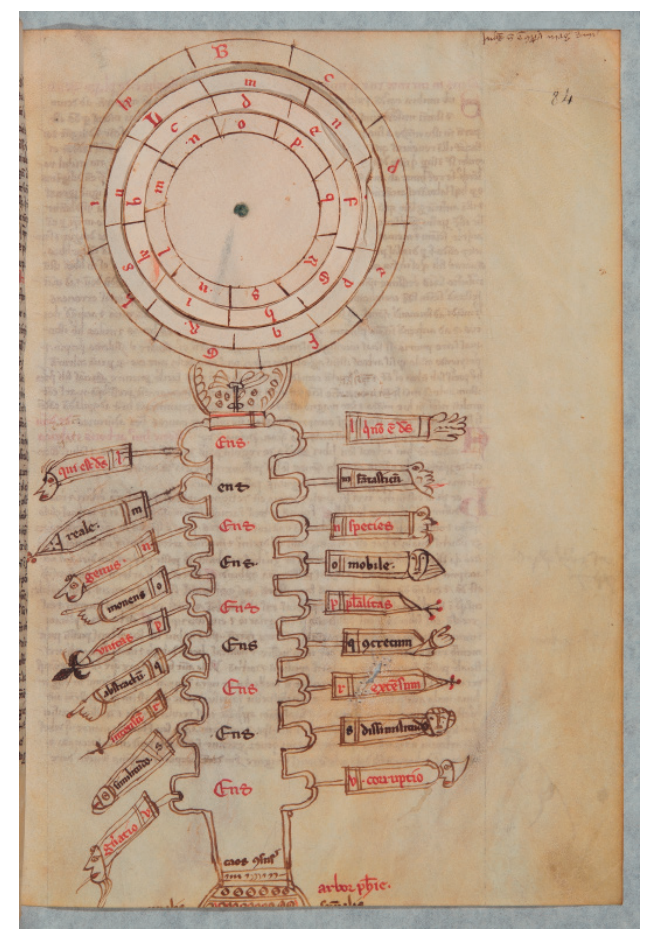

II. París, BNF, Lat. I6II6, f. 84r

(C) Bibliothèque Nationale, Paris http://tinyurl.com/gq8hyxh

28. Sembla que la darrera lletra hauria de ser una “t”, però és així, una “v” o "u”, en totes les fonts, com també en les figures que plasmen aquest text. Segurament és per evitar una de les dues úniques lletres que representen figures en l’Art ternària. L'altra, "a” de la primera figura, queda exclosa pel fet que el primer alfabet comença amb "b".

29. El ms. català de Munic afegeix una “r.”, que, a més de semblar errònia, és absent de les altres fonts medievals. 
Al manuscrit de Florència, al qual pertany la figura io, la volvelle ha anat a parar a un foli acarat (2I2r) a l'arbre. En canvi, el manuscrit de París, figura II, ha integrat en una sola figura arbre i volvelle. La diferència entre aquestes dues realitzacions és només un aspecte del problema de la plasmació gràfica de la descripció que acabem de donar, un problema que se centra en com mostrar els tres grups d'ítems que hem assenyalat amb les lletres A, B i C en la taula següent:

\begin{tabular}{|l|l|l|l|l|l|l|l|}
\hline $\mathbf{I}$ & $\mathbf{2}$ & $\mathbf{3}$ & $\mathbf{4}$ & $\mathbf{5}$ & $\mathbf{6}$ & $\mathbf{8}$ \\
\hline ens & q. és Déu & q. no és Déu & bonea & diferència & potència & $\mathrm{b}$ & $\mathrm{l}$ \\
\hline ens & reial & fantàstic & granea & concordança & object & $\mathrm{c}$ & $\mathrm{m}$ \\
\hline ens & q. és genus & q. és espècie & duració & contrarietat & memòria & $\mathrm{d}$ & $\mathrm{n}$ \\
\hline ens & movent & movible & poder & començament & intenció & e & o \\
\hline ens & unitat & pluralitat & saviea & mitjà & punt transcendent & f & p \\
\hline ens & abstracte & concret & volentat & fi q.é. perfecció & buit & g & q \\
\hline ens & intens & extens & vertut & majoritat & obra & h & r \\
\hline ens & q. és semblança & q. és dessemblança & veritat & egualtat & justícia & i & s \\
\hline ens & q. és generació & q. és corrupció & glòria & minoritat & orde & k & v \\
\hline & & & B & & C \\
\hline
\end{tabular}

A recull l'apartat [2] de la descripció, on l'arbre és presentat amb la seva "cana" (= tronc) de la columna I, i amb les seves "rames flors", que són els conceptes de les columnes 2-3.

B correspon a [4], que presenta els “comensaments" (= principis) o "flors d'aquest arbre”, és a dir els conceptes de les columnes 4-6.

G correspon a [3], això és, la volvelle, que desplega no conceptes sinó les lletres combinatòries de les columnes 7-8.

L'apartat [5] de la descripció explica com aquest darrer grup C està connectat amb els dos primers A i B. Però només ho explica donant-ne les equivalències ("“b· significa bontat e differencia e potencia”, etc.), sense dir ni una paraula sobre com cal representar visualment aquesta connexió.

El cas és que els copistes no han sabut on posar la volvelle de C. La majoria s'ha decantat per presentar-la separadament, que sembla la solució més adient, donat que la descripció no parla de cap connexió física amb l'arbre en el seu disseny. Les dues excepcions són el manuscrit parisenc de la figura II, que l'ha col-locat al capdamunt de l'arbre, com una mena de corona, i un ms. de la Universitätsbibliothek de Munic que l'ha situat a baix substituint les arrels de l'arbre..$^{30}$

El segon aspecte del problema és com representar la relació entre els grups A i B, que són els components de l'arbre. La majoria dels manuscrits opten per una solució com la del manuscrit parisenc de la figura II, que presenta un arbre format només amb A: col-locant al centre del dibuix el tronc amb la paraula "ens" repetida nou vegades (la columna I), amb les parelles de conceptes de les columnes 2 i 3 que en surten com a branques oposades, cada una amb la lletra corresponent de la columna $8 .{ }^{3 \mathrm{I}}$ Només dos manuscrits intenten dibuixar un arbre format amb A i B: el de Florència

3o. Munic, UB, $8^{\circ}$ Cod. 296, f. I7Iv. Succeeix que aquests dos còdexs (juntament amb el ms. Kues 83, que no ha transmès la volvelle) conformen una família que transmet una primera versió llatina de l’obra (Compagno-Roth ed. 2OII: 24).

3r. Els altres manuscrits medievals amb aquesta mateixa solució són: Munic, SB, Hisp 6o, f.rr; Munic, UB, Cod. $8^{\circ}$ 
que és el de la il·lustració Io, i el de Palma, Sant Francesc, ms. $7 .{ }^{32}$ En aquest cas, el tronc, també format amb la columna I, té els components d'A a la seva dreta, acompanyats pel mateix alfabet de la columna 8; i, a la seva esquerra, els components de B amb les lletres de la columna 7. S’esdevé, a més, que aquests dos còdexs són també els únics a dibuixar, a la base de l'arbre, el cap i el tors d'un home en actitud orant que suporta tota l'estructura arbòria, les arrels de la qual s'estenen fins als seus intel·lecte i memòria, com es pot observar a la il·lustració Io. ${ }^{33}$

La cosa que pot resultar més sorprenent de tot plegat és que, a les tres darreres distincions de l'obra, que formen el seu cos filosòfic i doctrinal, l'arbre que s'ha descrit amb tant de detall a la primera distinció no és pres en consideració, més enllà d'algun esment de passada de les flors (els principis). ${ }^{34} \mathrm{El}$ que realment interessa en les dinstincions centrals de l'Arbre de filosofia desiderat és el joc combinatori d'aquesta mena de reformulació de la Quarta Figura de l'Art ternària que és la volvelle. L'arbre no fa gaire més que presentar de manera amena i memorable els components que s'hi combinen. L’Arbre de filosofia, en conseqüència, no té el paper ontològic ni epistemològic que hem vist que tenia l'Arbre de ciència, que obligava el lector a meditar la relació de l'estructura arbòria amb el món real i conceptual que Llull descriu a l'obra homònima. L'arbre aquí és una eina mnemònica que Llull ofereix al seu fill perquè assimili els fonaments del discurs, que són els "començaments" de les columnes 4-6 de la taula més amunt, i la llista de subjectes de les columnes 2-3 als quals es poden aplicar. De fet, la representació de l'arbre vinculada gràficament amb el subjecte explícitament dibuixat amb les potències de la seva ànima que es fa la il.lustració IO, expressa de forma diàfana aquesta funció formativa de la figura: cal assimilar els continguts de l'arbre (en aquest cas els de les columnes A i B) per després poder fer funcionar la figura veritablement funcional que és la volvelle. El “desiderat” que conté el títol de l'obra probablement fa referència al desig i a la conveniència que aquest procés d'assimilació es dugui a terme.

Una altra singularitat de l'obra té a veure amb el fet que els límits del discurs ecfràstic que s’hi desenvolupa resulten difusos i que això produeix un determinat efecte en l'obra i en el lector. En primer lloc, hi ha un cert grau de confusió entre la figura de l'arbre objecte de descripció i l'“Arbre” entès com la totalitat de l'obra, que inclou la figura, és clar. ${ }^{35}$ Hi ha moments en què la veu narrativa en primera persona descriu ecfràsticament la figura de l'arbre, però també hi ha parts del discurs de l'obra en què no és clar si es refereix a la figura o al llibre, al tot o a la part. L'Arbre, en primera instància, és el text, no la figura:

Per asò, fil, qui segons cors de natura és a mi amable -e si és bo per virtut és ja a mi pus amable-, te

296, f. I7Iv; Bernkastel-Kues, Hosp, 83, f. I54v; Vaticà, Ottob. lat. I4O5, f.II8v; San Candido, VIII.B.I2, f. IIv.

32. Aquest ms. palmesà és reproduït, en una adaptació amb els conceptes traduïts al català, a Galmés ed. 1933: 405.

33. Al ms. de Sant Francesc, a més, la memòria i l’intel-lecte apareixen connectats per una lína vermella que descendeix fins al pit del subjecte on es llegeix un rètol amb el terme "voluntas". Pomaro (20I5: 264 i seg.) considera el ms. florentí un exemplar relacionable amb Llull mateix; fins a quin punt el redisseny de la figura i la inclusió del cap i del tors humans podrien tenir a veure amb aquest fet és una qüestió difícil de respondre per ara.

34. Per exemple, a la tercera distinció, que està basada en dos cercles de la volvelle, es diu que: "es de preposicions [= proposicions] ab les quals hom pot soure questions, les quals preposicions son conpostes dels comensamens e de les flors del arbre" (Galmés ed. 1933: 440). No hi haurà cap referència a les arrels.

35. Una cosa similar ja succeïa en el Llibre de contemplació (c. I272-74), que és la primera obra lul-liana que conté representacions gràfiques (vid. Soler-Bonner 20I6); el llibre IV s'estructura en sis distincions (XXXIII-XXXVIII), cadascuna de les quals tracta d'un arbre diferent i conté sis il-lustracions de sis arbres; tanmateix, en cap passatge del llibre IV no hi ha cap referència a les representacions gràfiques dels arbres (en cap moment s'arribarà a descriure la figura que acompanya el text): sempre que es parla d'“arbre" és per fer referència al discurs que es desenvolupa en les distincions. Fins a un cert punt, és el mateix que succeeix amb l'Ars compendiosa inveniendiveritatem, en què es produeix una identificació entre text i figures mitjançant la descripció de les figures, vid. Bonner-Soler 2007: 32. 
tramet aquest libre. [...] e moltes d'altres condicions, sapies, fil, ha en aquest libre que son bones e profitozes, les quals tu poràs saber e sentir si lo fruyt d'aquest Arbre saps culir conservar e amar. Per que jo·t fas manament, e.t don per conceil, que tu d'aquest Arbre sies agrícola tots los temps de ta vida; car per él poràs venir a la vida eternal si sots la sua ombra saps estar e del seu fruit manjar. (Galmés ed. 1933: 402)

Llibre, "arbre" i metàfora de l'arbre (que cal conrear, i del qual cal collir els fruits) són una mateixa cosa: conrear l'arbre vol dir llegir el llibre i assimilar-lo per conformar el funcionament de les potències de l'ànima segons el sistema de l'Art:

E saps, fil, per que los homens no saben uzar de memoria a membrar les cozes passades, ni uzar de l'enteniment a ensercar les cozes veres, ni de la volentat [a] eleger les cozes bones e leixar les males? Per so cor no saben aquestes potencies pozar en artefici, lo qual es estrument d'aqueles; e aquest Arbre es l'estrument que jo tramet a tu, fil, ab lo qual sabràs uzar de ton membrar entendre e amar, si ben lo sap apendre. (Galmés ed. 1933: 406)

D’altra banda, el discurs de l'Arbre de filosofia desiderat és desenvolupat per un jo narrador que també conté un remarcable grau d'indefinició. ${ }^{6}{ }^{2}$ 'una banda, es presenta emmarcat en un context narratiu que, en l'opus lul-lià, és un tòpic atribuït molts cops a Ramon: aquest personatge de ficció identificable amb l'autor de l'obra es troba en un locus amoenus, lluny del món -entès com l'àmbit en què lliura un combat per la reforma de la Cristiandat-, trist i decebut per la manca d'èxit en el seu projecte; ${ }^{37}$ en aquesta situació, per una raó o altra, Ramon troba la motivació per escriure el llibre que el lector té entre les mans i que representa la continuació, malgrat tot, de la seva missió (és el cas de l'Arbre de ciència o del Llibre de meravelles). De l'altra, aquest narrador en primera persona té traces d'una historicitat irrefutable: té un fill, que fa temps que no veu, i al qual li havia adreçat una obra seva, el Llibre d'intenció; aquest noi és també el receptor del text i, en un moment determinat, el seu pare-narrador fa referència a un episodi personal, que els concerneix tots dos, i que fa més comprensible un determinat punt del seu discurs: la mare d'aquest noi, i esposa del narrador, ja fa temps que ha mort.$^{38}$ La veu narrativa, per tant, es troba en un pla ambigu entre la realitat i la ficció; així, per exemple, afirma que la inspiració per escriure l'Arbre de filosofia desiderat, l'obra que el lector té efectivament a les mans, la troba en l'arbre que l'acull en el verger de ficció.

Però no és només el jo narrador que presenta un caràcter difús. El mateix succeix amb el tu al qual s’adreça, el seu fill, que rep un tractament que el situa també entre ficció i realitat. D’una banda, hi ha els detalls històrics als quals ens acabem de referir i que fan que el destinatari només pugui ser Domingo, el fill de Ramon Llull; però de l'altra, el fet que el narrador inclou el seu receptor en la ficció de la descripció del funcionament de la seva obra i que això el despersonalitza i el converteix en un tu tipificat:

... e aquest Arbre es l'estrument que jo tramet a tu, fil, ab lo qual sabràs uzar de ton membrar

36. Claire Barbetti (20II: 32-37) s'ha referit a la subjectivitat difusa de les descripcions ecfràstiques de les visions en somnis com una característica pròpia de l'ús d'aquest recurs retòric a l'Edat Mitjana.

37. "Dementre que estava en aquesta trista consideració, per la presencia del arbre sots lo qual estava, volentat me venc que feés aquest Arbre ..." (Galmés ed. I933: 4OI). "Fer aquest Arbre” vol dir escriure el llibre que envia al seu fill.

38. L’original català del passatge "Consira, fil, en .iij. maneres fi, so es a saber, fi que es de privació de les cozes que eren e no son, axí com la tua mare que sulia eser e es fenida [...]” (Galmés ed. 1933, 4I5) es converteix en l’edició llatina en "Fili carissime, consideres tribus modis finem: primo scilicet finem, qui est priuatio illorum, qui fuerunt et non sunt, sicut materia tua, quae fuit et modo non est." (Compagno-Roth ed. 20II, 59). Tanmateix, els quatre manuscrits llatins més antics de l'obra semblen llegir mater i no materia. 
entendre e amar, si ben lo saps apendre. L'aiga ab que tu deus regar aquest Arbre ix de tres fons, so es assaber, fe speransa e karitat; e d'aquest flum que ix d'aquestes tres fons, ixen .iiij. rius, los quals son justicia prudencia fortitudo e tempransa; e tu deus regar aquest arbre .x. vegades, segons que son los .x. manamens, e deus donar del seu fruit .vij. vegades segons los .vij. dons de sant Spirit. ${ }^{39}$

La subjectivitat difusa que condueix el discurs i la que n'és destinatària, al costat d'una aplicació de l'ècfrasi que presenta també uns límits imprecisos, creen un objecte ecfràstic especialment complex i versàtil, capaç de transmetre al lector la complexitat i el dinamisme de l'activitat mental que descriu i que vol aconseguir en el lector. ${ }^{40}$

\section{A mode de conclusió}

C Com hem vist, en les obres de Ramon Llull hi ha una casuística molt variada pel que fa a la presentació de recursos diagramàtics mitjançant figures gràfiques o descripcions verbals. Hi ha descripcions extenses de figures que han estat representades gràficament en els manuscrits, com l'Arbre dels Començaments de medicina; però també descripcions de figures que són irrepresentables, com l'Arbre de l'Arbre de ciència. També hi ha descripcions tan escarides que resultarien del tot insuficients si haguessin de servir perquè hom pogués fer la versió gràfica d'una figura, com la de l'Ars compendiosa, en què es limita a dir "Prima figura de bonitate, magnitudine, etc., usque ad gloriam est constituta". ${ }^{41}$ I, de la mateixa manera, trobem discursos ecfràstics que desborden la pura funcionalitat descriptiva, com el de l'Arbre de filosofia desiderat.

Aquesta realitat tan canviant fa que ens preguntem per què Llull tendia a combinar, de manera variable, descripció verbal i representació plàstica de les figures. Segurament no hi ha una única resposta. En alguns casos aquest doble procediment, descripció i representació, podia tenir una funció preventiva davant de la possibilitat que, als manuscrits, les representacions visuals, per raons diverses, poguessin quedar per fer, que no fossin fetes de manera adequada, o que s'arribessin a perdre. $4^{2}$

39. Galmés ed. 1933: 406. Vid. també: "Per que jo·t fas manament, e·t don per conceil, que tu d'aquest Arbre sies agrícola tots los temps de ta vida” (ibid., 402).

40. És una aplicació que pot relacionar-se amb la caracterització que fa Barbetti d'aquest tipus de discurs:

"Ekphrasis does not construct a rigid body. Its principle rather is to create relationships, connections. The ekphrastic body expands; its contemplative functioning is a mode of becoming rather than attempting to fix. It re-sees, re-perceives compositions; it assimilates, restructures, and makes something new, something that shares some of the skins and curves of its "object" (for lack of a better word) but has stretched them into new shapes and dimensions" (20II: 27). La mateixa autora subratlla que el discurs ecfràstic, a l'Edat Mitjana, "is less concerned with representing physical manifestations of art than it is with exploring the spaces in which the human intellect and soul are formed and in turn inform each other, especially at the communal level” (ibid., 9).

4I. L'única edició accessible de l'obra és la d'Ottaviano (I930), però atesa la poca fiabilitat que té, hem utilitzat una edició mecanografiada de Fernando Domínguez que es troba dipositada al Raimundus-Lullus-Institut de Freiburg. Un altre cas com aquest seria el de la primera figura de l'Ars inventiva veritatis, en què només es dóna una llista dels nou principis de l'Art amb les seves lletres corresponents (Uscatescu ed. 20I4: Io).

42. Cosa que passava sovint. Al Liber propositionum secundum Artem demonstrativam compilatus, per exemple, les figures -tan complicades i necessàries- només són presents en tres dels vint-i-set manuscrits medievals: al de Venècia (Marciana, Lat VI, 200), al de Milà (Ambrosiana, P I98 Sup.) i al d’Uppsala (Universitetsbiblioteket, C 5ㅍ. També hi ha manuscrits en els quals les parts geomètriques s'han dibuixat però han quedat buides, sense els termes que els donen sentit. En altres casos, ha desaparegut el quadern inicial del manuscrit en què hi havia l'aparell gràfic, com a l'únic testimoni de la versió catalana de l'Art demostrativa, a Mainz (Martinus-Bibliothek, ms. 22oh). També hi ha el cas curiós del ben conegut manuscrit Bernkastel-Kues, 83, amb bellíssimes figures als dos primers folis que no tenen res a veure, 
Deixant de banda l'aspecte pràctic de l'assumpte, és evident que la descripció verbal, sigui extensa o breu, subratlla la importància de les figures, de manera que el lector no passi per alt que són l'eina fonamental per organitzar i codificar els fonaments de tot l'aparat combinatori de l'Art, que són els elements que articulen el seu raonament diagramàtic.

Però potser més important -per les vegades que hi insisteix- és la dimensió cognitiva de la qüestió. Hi ha una raó mnemònica, de recurs que ajuda a la memorització de les imatges. A la mateixa Art demostrativa es diu: "Dit havem de les quatre figures, les quals convé esser sabudes de cor, sens les quals l'artista no pot bé usar ne praticar de aquesta Art” (Bonner ed. rg89: I, 547).

Perquè, d'altra banda, les figures, la seva morfologia, la seva visualització material i mental i l'assimilació del seu funcionament, és allò que permet que hom elevi l'ànima al coneixement intel·lectual i a la contemplació espiritual:

Honrat Senyor, qui vol adorar e contemplar la vostra sancta veritat, cové que afigur figures sensuals per les quals pusca pujar a les figures entel-lectuals ab les quals pusca e sàpia e vulla adorar e contemplar la vostra veritat vertuosa. (Llibre de contemplació, Llull I957-6o: 2, I080).

La intenció per que nos posam figures en esta Art, es per ço que en elles esguardem los començaments d'esta Art: car per la especulació sensual s'exalça l'enteniment a especular les coses sperituals, per lo qual exalçament se exalça la volentat a amar aquelles. (Art amativa, Galmés ed. I933: 9).43

De vegades combina les dues raons:

Intentio quare in hac Arte figurae traditae sunt est ut per sensum imaginatio, et per imaginationem intellectus sentiat auxilium, et maxime ut per eas universalia principia in eis appareant, et ad memoriam facilius reducantur. (Compendium seu commentum Artis demonstrativae, Salzinger-Wolff ed. I722: vi, I, 293. $)^{44}$

Aquests passatges posen de manifest que les figures mateixes són esglaons en una pujada que vol arribar a "adorar e contemplar" les veritats divines, o a entendre "les coses sperituals, per lo qual exalçament se exalça la volentat a amar aquelles". Així que, tant en la seva dimensió plàstica com en la seva dimensió ecfràstica, les figures són una eina que ajuda a la meditació i a la contemplació, en l'àmbit intel-lectual i en l'espiritual, $\mathrm{o}$, com diu el beat, tant en la ciència com en l'amància. Les descripcions, per tant, compleixen amb la funció d'exercici meditatiu que a l'Edat Mitjana es reservava a l'ècfrasi (Carruthers 2006: 288-89). Llull, tanmateix, vol afegir una qualitat a aquest procés d'elevació del coneixement, que és l'estructuració i la sistematització d'aquests exercicis meditatius segons el mètode de la seva Art.

Les apel-lacions que Ramon fa a la indefugible implicació del lector en el procés d'elevació de la seva ànima són variades i constants: de vegades es tracta de plantejar una aparent obscuritat del

ni pel contingut ni per l'estil paleogràfic, amb la resta d'aquest manuscrit cusà; semblen una importació d'un ms. italià que les deu haver "perdudes".

43. El text equivalent de l'Ars inventiva veritatis és bastant similar (vid. la citació corresponent a la nota 53). Pel que fa a la citació de l'Art amativa, cal tenir en compte la definició que dóna Albert Blaise (i975: s. v.) de speculatio: “I. spéculation, action de l’intellect qui se repose dans la seule connaissance de la vérité. 2. contemplation” (amb citacions de Sant Tomàs i Hug de Sant Victor).

44. Vid. també el passatge al principi de l'ècfrasi dels Començaments de medicina citada més avall. Un altre procés és descrit al Liber propositionum secundum Artem demonstrativam compilatus, en el qual cada figura és tractada de tres maneres: com a figura sensitiva, figura imaginativa i figura intel-lectual; vid. Salzinger-Wolff ed. I722: viii, 2-7 (5O4-O9). 
discurs proposada com un repte intel-lectual a superar; ${ }^{45}$ d'altres, es tracta de deixar obert el final d'una obra, sense solució aparent, per tal que el lector hagi de trobar-lo, com en el cas tan celebrat del Llibre del gentil; ${ }^{6} 6$ o, encara, de proposar un notable aparat de qüestions i de respostes que permetin assimilar una determinada versió de l'Art. Aquest darrer recurs forma part d'un programa molt més general que ell anomena "habituació”, que consisteix no només a trobar solucions a qüestions, sinó a formular i solucionar qüestions noves, que el lector ha de plantejar pel seu compte; com diu en el penúltim apartat gairebé idèntic de l'Art breu i de l'Ars generalis ultima:

Aquesta part és de la habituació d'aquesta Art, e aquesta és departida en tres parts, la primera de les quals és de les tretze parts en les quals aquesta Art és departida. E aquelles deu habituar lo artista d'aquesta Art, per ço que ell sàpia aplicar la qüestió a aquell loc o locs a la qüestió dispost o disposts, segons la proporció de la matèria de la qüestió.

La segona part és que habituu la manera e lo procés del text d'aquesta Art, tinent la manera del text a provar e solre les qüestions peregrines per aquella manera per la qual són explicades en lo text, així com un exempli lo qual per altre és exemplificat e declarat.

La terça part és que ell haja manera de multiplicar les qüestions e les solucions a una mateixa conclusió ...47

Llull espera del lector una actitud proactiva respecte de l'Art; és a dir, que faci funcionar unes figures que expressen la connectivitat essencial del sistema, de manera que desenvolupi processos dinàmics i oberts de coneixement: que participi de l'acte de trobar (invenire) preguntes i formular respostes (demostracions) noves..$^{4} \mathrm{I}$ és precisament amb aquesta dimensió inventiva de les figures lul-lianes, que no són de cap manera un mer ajut mnemònic, que connecta l'ècfrasi com a recurs retòric amb capacitat inventiva (Carruthers 1998: 2OO-OI).

Les figures, en elles mateixes, no són representacions de res: només existeixen pròpiament tal com Llull les va idear quan hom les fa funcionar. En l'acte de la seva aplicació, l'Art representa el dinamisme mental, en correspondència amb el dinamisme de l'ésser. Es pot dir que l'Art no està en els manuscrits, ni en les figures gràfiques materialment reproduïdes en el llibre ni en les exposicions que les descriuen, sinó en el cap de qui l'ha interioritzat, i raona d'acord amb ella. En efecte, l'aspiració de Llull era que hom aprengués de cor els mecanismes de l'Art de manera que pogués fins i tot prescindir de la representació material de les figures:

Ratio autem, quare figurae praedictae positae sunt in hac Arte, stat in hoc, ut sensus situm et dispositionem illarum apprehendat, eo quod in illa apprehensione imaginatio sit speculum, in quo intellectus dispositionem figurarum principiorum huius artis et eius modum discursivum et

45. Així al capítol I4 del Llibre de meravelles el protagonista no aconsegueix d'entendre què és un àngel a través d'un relat que li proposa l'ermità i a partir del qual hauria de poder-ho deduir per analogia proporcional (la cursiva és nostra): “-Senyer -dix Felix al sant hermitá-, molt me maravell de vostres eximplis, cor vijares m’es que no facen res al proposit de que yo us deman. -Bell amich -dix l'ermitá-, scientment vos faç aytals semblançes per ço que vostre enteniment exalçets a entendre; cor on pus escura es la semblança pus altament enten l'enteniment qui aquella semblança enten" (Badia et al. ed. 2OII-I4: I, I49). Sobre el recurs a l'obscuritat vid. Santanach 2OI5.

46. Vid., al Llibre del gentil, el discurs que fan els tres savis al final de l'obra sobre les raons per què no volen saber quina religió ha triat el gentil (Bonner I989: I, 268-7I).

47. Vid. Bonner r989: I, 597; Madre ed. r986: 523-24; i Madre ed. r984: 253.

48. Consells similars es troben a altres obres, com per exemple a l'Art demostrativa. Una situació anàloga es troba al Llibre de meravelles, on s'encomana al nou Fèlix la tasca de trobar (invenire), no noves combinacions artístiques per formular noves qüestions i solucions, sinó nous exemples que, de fet, porten a les mateixes conclusions. Per a l'Art demostrativa, vid. Bonner I989: I, 395. Per aquesta qüestió en general, vid. Bonner 2012: 329-32. 
investigativum attingat. ${ }^{49}$

Representació i descripció són recursos complementaris per assolir aquest objectiu. Pot succeir, però, com en el cas de l'Arbre de ciència, que la capacitat mental de l'autor per concebre una figura multidimensional desbordi les possibilitats reals de representació i, llavors, que la descripció ecfràstica sigui el vehicle més adequat per induir el lector a representar la figura en la seva ment. D’altra banda, l'ècfrasi no és només un trasllat simple d'una imatge d'un objecte -mental o real-a un discurs verbal, sinó que també desenvolupa possibilitats hermenèutiques que la sola imatge no té, com hem vist que succeïa en el cas de la reformulació de la Figura A de l'Art quaternària i en les Arts ternàries.

\section{Annex: Descripció de l'arbre dels Començaments de medicina}

Capítol I. De la disposició de la art ${ }^{50}$

Natura es d'enteniment que entena mils per demostració feta per vista et per oiment, que per oir tan solament..$^{5^{\mathrm{I}}}$ Et per asò nos, al comensament d'aquest libre formam .i. arbre segons esta manera, per tal que ab les flors demostrem veritat de so que ensercam a l'umá enteniment, lo qual arbre es apelat Arbre dels comensamens de medissina.

La rail de l'arbre es . $i^{\text {a }}$. roda composta de letres significans les .iiii. humors, et per asó es departida en .iiii. partz: la primera part es de la colera, segona es de la sanc, tersa es de la fleuma, quarta es de malencolia, on en quada quadrangle es demostrada la operació de la humor et la febra, et lo mesclament de los elemens, et la major accessió de la febra, et les altres coses qui·s contenen en les condicions de l'arbre.

A fer et a formar les demostracions qui.s covenen a aquesta art, sostzposam .A. esser calor, .B. secor, .C. humiditat, .D. fredor. Et d'aquestes letres componem los quadrangles de la roda segons que.s mesclen les humors et segons que les unes an acció o passió en les altres. Et asó t'es demostrat en la rail de l'arbre.

De la rail nexen .ii ${ }^{\text {es }}$. branques. La primera es dels comensamens de medicina, segons que es recomptat per los antics qui son passatz. Aquela branca es en .iii. partz: la primera es natural, la segona es innatural, tersa es contra natura. La natural a .vii. flors: elemens, complecions, humors, membres, vertutz, operacions, esperit. Item a en la dita branca .iiii. flors, so es a ssaber: etat, color, diversitat de mascle et de femna, et forma. La innatural n’a .vi.: aer, exarsisi et repós, menjar beure, vetlar dormir, conplir e buydar, accidens d'anima, so es gog et tristicia. La tersa branca n'a .iii.: malautia, causa, accidens.

La segona branca es novelament atrobada a espondre la primera artificialment et mataforicalment, et es departida en .ii. partz. La primera part es departida en A.B.C.D.; la segona es departida en los .iii. triangles qui son en los comensamens de la Art abreujada d'atrobar veritat, et en .i. quadrangle de la figura de predestinació, la qual se conté en la art damunt dita.

La .A. es departida en .iiii. graus demostratz per les figures d'argorisme, so es a ssaber, en 4, 3, 2, I, et asó metex se segex de .B.C.D. On, a demostrar los graus damunt ditz, cové elegir .xvi. erbes en general, et cascuna do significació de les altres herbes qui son de sa complecció. Et

49. Ars inventiva veritatis, Uscatescu ed. 20I4: 9. En Llull sempre hi ha una voluntat de superar el nivell del coneixement sensible i d'elevar-se cap al coneixement intel-lectual. Al Llibre de contemplació, tem que l'ús de figures sigui un destorb per al lector que ha de fer aquest camí (Llull I957-60: 2, 489).

50. El text és pres de Badia ed. 2002: 44-46. Vid. també Bonner I989: 2, 409-I4, i la versió llatina a Sánchez Manzano ed. 20o6: $43^{8-45}$.

5I. "Oiment" i “oir", en una època que la lectura sovint era a veu alta, eren els equivalents de "lectura" i "llegir". 
cascuna de les .xvi. herbes sia nomenada per letra a el'apropriada per discripció, per tal que mils et pus abreujadament s'en pusca fer demostració. E cové que en les letres no sia .i. qui-s sembla ab lo primer nombre d'argorisme, ni no y sia .x. qui significa nombre de deu.

Lo nom de les herbes et de les letres es aquest. Nos sotzposam et deim que .E. es .ia. especia de simpla medicina, et es en 4 grau de .A., et en 3 de .B., et en 2 de .C., et en I de .D. La .F. es altra especia, qui es en 3 de .A., en 2 de .B., en I de .C.. La .G. es altra especia qui es en 2 de .A., et en I de .B. La.H. es altra especia qui es en i de.A.

.K. es altra especia qui es en 4 grau de .B., et en 3 de .D., et en 2 de .A., et en I de .C. La. L. es altra especia qui es en 3 grau de .B., et en 2 de .D., et en I de .A. La .M. es altra especia qui es en 2 grau de .B., et en I de .D. La .N. es altra especia qui es i grau de.B.

.O. es altra especia qui es en 4 grau de .C., et en 3 de .A., et en 2 de .D., et en I de .B. La.P. es altra especia qui es en 3 grau de .C., et en 2 de .A., e en I de .D. La.Q. es altra specia que es en 2 de .C., et en I de .A. La.R. es altra especia qui es en i grau de .C.

.S. es altra especia qui es en 4 grau de.D., et en 3 de .C., et en 2 de .B., et en I de .A. La.T. es altra especia qui es en 3 grau de.D., et en 2 de .C., et en I de .B. La.V. es altra especia qui es e 2 grau de .D., et en i de .C. La.Y. es altra especia que es en lo i grau de .D. Per estes letres decorre esta art, et sens que hom no sapia les letres no enten la art.

Cascuna de les letres cové esser flor en l'arbre, et cové aver apropriada color la letra et sos graus, per so que les letres e los graus se covengen a fer la demostració. On per asó nos apropriam a la .A.E.F.G.H. color vermela, et aquesta color metexa donam als graus qui son de calor. A la .B.K.L.M.N. donam color negra, et asó metex als graus qui son de seccor. A la .C.O.P.Q.R. donam color blava, et asó metex de los graus qui signifiquen humiditat. A la .D.S.T.V.Y. donam color vert, et a los graus qui son de fredor.

Lo triangle vermel es en .iii. flors: comensament et mijá et fi. Et lo triangle vert es en altres .iii. flors, so es a ssaber: diversitat, concordansa, contrarietat. Lo triangle groc es departit en altres .iii. flors, so es a ssaber: en majoritat, egualtat, menoritat.

Lo quadrangle es departit en .iiii. flors: esser, privació, perfecció, defaliment. Esser es de color vermela, et perfecció de color blava, et privació de color negra, et defaliment de color vert.

Qui aquesta art vol entendre ni saber, a ssaber li cové l'alfabet damunt dit, et cové que les flors de l'arbre translat en altres flors movables et entalades, per tal que pusca demostrativament mesclar et formar et egualar et crexer o minvar les unes ab les altres. 


\section{Obres citades}

Badia, Lola (ed.). 2002. Ramon Llull Començaments de medicina; Tractat d'astronomia, Nova Edició de les Obres de Ramon Llull, 5 (Palma: Patronat Ramon Llull)

Badia, Lola; Bonillo, Xavier; Gisbert, Eugènia; Fernàndez Clot, Anna; Lluch, Montserrat (ed.). 2OII-I4. Ramon Llull Llibre de meravelles, vol. I: Llibres I-VII; vol. 2: Llibres VIII-X, Nova Edició de les Obres de Ramon Llull, Io \& I3 (Palma: Patronat Ramon Llull)

Barbetti, Claire. 20II. Ekphrastic Medieval Visions: A new discussion in interarts theory (New York: Palgrave Macmillan) <http://dx.doi.org/IO.IO57/978023037053I>

Blaise, Albert. 1975. Lexicon Latinitatis Medii Aevi (Turnhout: Brepols)

Boadas, Agustí (ed.). 1994. Bonaventura Soliloqui i altres escrits, Clàssics del Cristianisme, 44 (Barcelona: Proa)

Bonner, Antoni (ed.). 1989. Obres selectes de Ramon Llull (1232-1316), 2 vols (Palma: Moll)

Bonner, Anthony. 2002. 'The structure of the Arbor scientiae', in Arbor Scientiae: der "Baum des Wissens" von Ramon Lull: Akten des Internationalen Kongresses aus Anlass des 4o-jährigen Jubiläums des Raimundus-Lullus-Instituts der Universität Freiburg i. Br., ed. by Fernando Domínguez Reboiras, Pere Villalba Varneda, and Peter Walter (Turnhout: Brepols) pp. 2I-34

Bonner, Anthony. 20I2. L'Art i la lògica de Ramon Llull: manual d'ús, Col.lecció Blaquerna, 9 (Barcelona: Universitat de Barcelona; Palma: Universitat de les Illes Balears)

Bonner, Anthony; Soler, Albert. 2007. 'La mise en texte de la primera versió de l'Art: noves formes per a nous continguts', Studia Lulliana, 47: 29-50 <http://tinyurl.com/h4eym6l $>$

Bonner, Anthony; Soler, Albert. 20I5. 'Les figures lul-lianes: la seva naturalesa i la seva funció com a raonament diagramàtic', Studia Lulliana, 55: 3-30 <http://tinyurl.com/z6jecfy $>$

Carruthers, Mary. 1998. The Craft of Thought: Meditation, rhetoric, and the making of images 4oo1200 (Cambridge: Cambridge University Press)

Carruthers, Mary. 2006. 'Moving Images in the Mind's Eye', in The Mind's Eye: Art and theological argument in the Middle Ages, ed. by Jeffrey F. Hamburger and Anne-Marie Bouché (Princeton: Princeton University Press), pp. 287-305

Compagno, Carla; Roth, Ulli (ed.). 2OII. Raimundi Lulli Opera Latina, Tomus XXXIV, 61-63: Annis 1294-1295 composita, Corpus Christianorum Continuatio Mediaevalis, 246 (Turnhout: Brepols)

Cruz Hernández, Miguel. 1977. El pensamiento de Ramon Llull (Madrid: Fundación Juan March; Editorial Castalia)

Galmés, Salvador (ed.). 1932. Ramon Lull Art demostrativa; Regles introductòries; Taula general, Obres de Ramon Llull, i6 (Palma)

Galmés, Salvador (ed.). 1933. Ramon Lull Art amativa; Arbre de filosofia desiderat, Obres de Ramon Llull, I7 (Palma)

Galmés, Salvador (ed.). 1935. Ramon Lull Libre d'intenció; Arbre de filosofia d'amor; Oracions e contemplacions del enteniment; Flors d'amors eflors d'entelligència; Oracions de Ramon, Obres de Ramon Llull, i8 (Palma) 
Llull, Ramon, I957-I96o, Obres essencials, 2 vols. (Barcelona: Selecta)

Madre, Alois (ed.). I98I, Raimundi Lulli Opera Latina, Tomus IX, 12O-122, in Monte Pessulano anno MCCCV composita, Corpus Christianorum Continuatio Mediaevalis, 35 (Turnhout: Brepols)

Madre, Alois (ed.). 1984. Raimundi Lulli Opera Latina, Tomus XII, 123-12\%, Barcinone, in Monte Pessulano, Pisis annis MCCCV-MCCCVIII composita, Corpus Christianorum, Continuatio Mediaevalis, $3^{8}$ (Turnhout: Brepols)

Madre, Alois (ed.). I986. Raimundi Lulli Opera Latina, Tomus XIV, 128, Ars Generalis Ultima, MCCCV-MCCCVIII, Lugduni anno MCCCV incepta, Pisis anno MCCCVIII ad finem perducta, Corpus Christianorum Continuatio Mediaevalis, 75 (Turnhout: Brepols)

Ottaviano, Carmelo. I93o. L“Ars compendiosa” de R. Lulle, avec une étude sur la bibliographie et le fond Ambrosien de Lulle (Paris: Vrin)

Pimentel, Aurora Luz. 200I. El espacio en la ficción, ficciones espaciales: la representación del espacio en los textos narrativos (México: Siglo XXI)

Pomaro, Gabriella, 20I5. 'Un caso particolare: dentro lo scriptorium lullianum', in Scriptoria e biblioteche nel Basso Medioevo: atti del LI Covegno storico internazionale, Toddi 2014 (Spoleto: Fondazione Centro Italiano di Studi sull'Alto Medioevo), pp. 243-84

Rubio, Josep E. 1997. 'Una incursió lul-liana en l'ars memoriae clàssica al Llibre de contemplació en Déu', in Actes de l'Onzè Col-loqui Internacional de Llengua i Literatura Catalanes, Palma 1997, vol. I, ed. by Joan Mas i Vives, Joan Miralles i Monserrat, and Pere Rosselló Bover (Barcelona: Publicacions de l'Abadia de Montserrat), pp. 6I-72

Rubio, Josep E. 2007. 'Un capítol en l'ús de l’al-legoria en Ramon Llull: exegesi del capítol 354 del Llibre de contemplació, Studia Lulliana, 47: 5-27 <http://tinyurl.com/gwnyz3o $>$

Rubio, Josep E. (ed.). 2007. Raimundi Lulli Opera Latina, Tomus XXXII, 27. Ars demonstrativa, Corpus Christianorum Continuatio Mediaevalis, 2I3 (Turnhout: Brepols)

Salonius, Pippa; Worm, Andrea. 20I4. 'Introduction', in The Tree: Symbol, allegory, and mnemonic device in medieval art and thought, ed. by Pippa Salonius and Andrea Worm (Turnhout: Brepols), pp. I-I2 $\langle$ http://dx.doi.org/IO.I484/m.imr-eb.I.IO2OIg $>$

Salzinger, Ivo; Wolff, Franz Philipp (ed.). I722. Beati Raymundi Lulli Opera, vol. 3 (Moguntiae) $\langle\underline{\text { http://tinyurl.com/j4qvty7 }>}$

Sánchez Manzano, María Asunción (ed.). 20o6. Raimundi Lulli Opera Latina, Tomus XXXI, 12-15. Quattuor libri principiorum, Corpus Christianorum Continuatio Mediaevalis, I85 (Turnhout: Brepols)

Santanach i Suñol, Joan. 20I5. 'Ramon Llull i l'obscuritat que il.lumina: apunts sobre l'origen i rendibilitat literària d'un recurs exegètic', Anuario de Estudios Medievales, 45/I: 33-354 $\langle\underline{\text { http://dx.doi.org/IO.3989/aem.2OI5.45.I.II }>}$

Soler, Albert. 2006a. 'Estudi històric i codicològic dels manuscrits lul-lians copiats per Guillem Pagès (ca. I274-I3OI)', Arxiu de Textos Catalans Antics, 25: 229-66 < $\underline{\text { http://tinyurl.com/ }}$ zpoblzx $>$

Soler, Albert. 2006b. 'El "llibre cortès de lectura" en català: a propòsit del manuscrit F-I29 del Col-legi de la Sapiència de Palma", Caplletra, 4I: 9-42 $\langle\underline{\text { http://tinyurl.com/zedbge6 }>}$

Soler, Albert. En premsa. 'El llibre que Ramon Llull mai no va escriure: figures imaginàries i 
diagramàtica en l'opus lul·lià', Estudis Franciscans

Soler, Albert; Bonner, Anthony. 20I6. 'Les representacions gràfiques al Llibre de contemplació de Ramon Llull', in Els manuscrits, el saber i les lletres a la Corona d'Aragó, 1250-1500: Jornada d'Estudi dels Grups Narpan \& Sciència.cat, (Barcelona: Publicacions de l'Abadia de Montserrat), pp. $2 \mathrm{I} 3-44$

Uscatescu, Jorge (ed.). 20I4. Raimundi Lulli Opera Latina, Tomus XXXVII, 44. Ars inventiva veritatis, Corpus Christianorum Continuatio Mediaevalis, 265 (Turnhout: Brepols)

Villalba, Pere (ed.). 200o. Raimundi Lulli Opera latina, Tomi XXIV-XXVI, 65. Arbor scientiae. Romae in festo sancti Michaelis archangeli anno MCCXCV incepta, in ipsa urbe Kalendis Aprilibus anni MCCXCVI ad finem perducta, Corpus Christianorum Continuatio Mediaevalis, Ioo A-C (Turnhout: Brepols) 